\title{
Comprehensive study and optimization of concentrated photovoltaic- thermoelectric considering all contact resistances
}

(i) The corrections made in this section will be reviewed and approved by journal production editor.

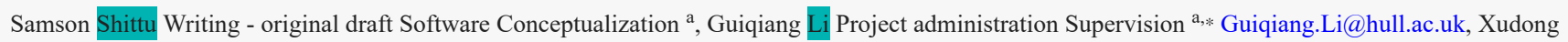

Zhao Funding acquisition ${ }^{\text {a,b }, *}$ Xudong.Zhao@hull.ac.uk, Xiaoli Ma Writing - review \& editing a , Yousef Golizadeh Akhlaghi Formal analysis a , Yi Fan

Visualization $^{\text {a }}$

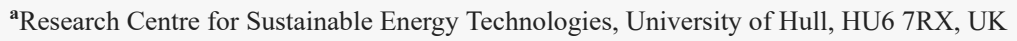

${ }^{\mathbf{b}}$ Department of Power Engineering, North China Electric Power University, China

*Corresponding authors.

\begin{abstract}
A consequence of the integration of photovoltaic module and thermoelectric generator is the presence of thermal contact, which affects the heat transfer in the hybrid system. Thermal and electrical contact are inevitable in a thermoelectric generator and their effects on the performance of the thermoelectric generator can be significant if not properly managed. Therefore, this study presents a comprehensive three-dimensional numerical investigation on the effect of contact resistances on the performance of concentrated photovoltaic-thermoelectric using COMSOL 5.4 Multiphysics software. Four contact resistances are studied including thermoelectric thermal contact resistance, thermoelectric electrical contact resistance, photovoltaic-thermoelectric interface thermal contact resistance and thermoelectric generator-heat sink interface thermal contact resistance. Twelve contact resistance cases are considered, and a comparison study is presented to investigate the most important contact resistance. In addition, a parametric optimization study is performed to investigate the optimum values for thermoelectric leg height, load resistance, concentration ratio and convective heat transfer coefficient. Results show that ignoring all contact resistances in the hybrid system causes an overestimation of overall power output and efficiency by $7.6 \%$ and $7.4 \%$ respectively using the base values considered in this study. In addition, the thermal contact resistance between the thermoelectric generator and heat sink, and that between the photovoltaic-thermoelectric interface are found to be the most important contact resistances, which should be reduced. Furthermore, results show that the optimum thermoelectric external load resistance in a hybrid system is lower than that of the thermoelectric generator only system. This study will provide valuable guidance on photovoltaic-thermoelectric accurate modelling.
\end{abstract}

Keywords: Photovoltaic-thermoelectric; Contact resistance; Thermal contact; Electrical contact; Finite element method

\section{Nomenclature}

$\mathrm{C}$

$C_{P}$

$\mathrm{G}$

$\mathrm{h}$

$h_{\text {sink }}$

I

$\mathrm{P}$

$P_{\text {gen }}$

$q$

$R_{c}$

$R_{\text {cont }}$

$\mathrm{R}_{\text {in }}$

$\mathrm{R}_{\mathrm{L}}$

$R_{p v_{-} t e}$

$R_{\text {teg_hsink }}$

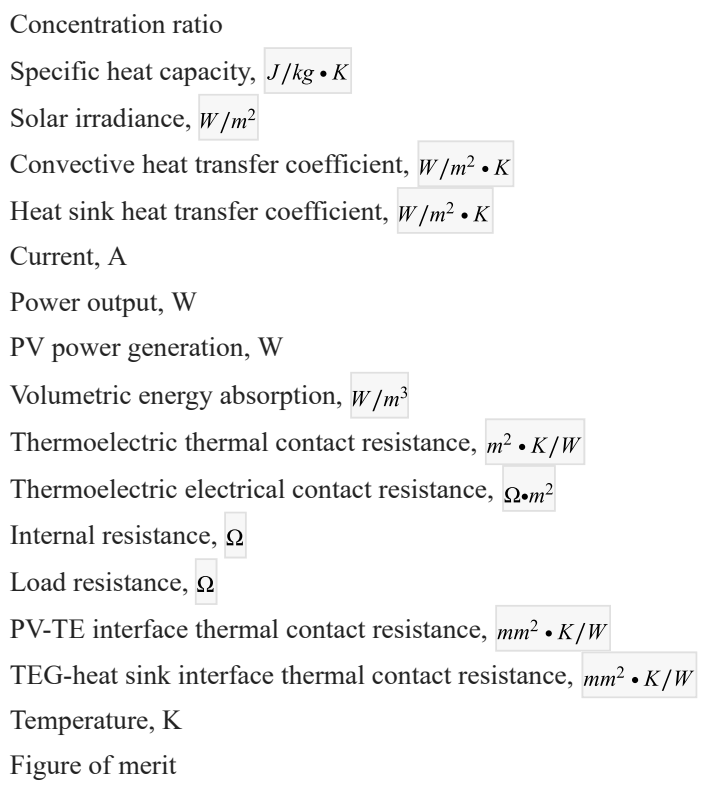




\section{Greek symbols}

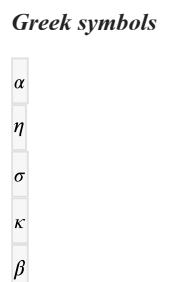

Abbreviations

Abbreviations

PV-TE

TE

TEG

TPT

\section{Subscripts}

$\begin{array}{ll}\text { Subscripts } & \\ \text { a } & \text { Ambient } \\ \text { pv } & \text { PV cell } \\ \text { sky } & \text { Sky }\end{array}$

\section{Introduction}

Renewable energy sources are eco-friendly and do not cause serious environmental issues like climate change and air pollution therefore, there is a recent paradigm shift from fossil fuels to renewable energy sources like solar energy [1,2]. Generally, solar power can be divided into non-concentrating (e.g. flat-plate photovoltaics) and concentrating solar power systems [3]. Photovoltaic (PV) can provide direct conversion of solar energy into electricity via the Photovoltaic effect [4] however, the conversion efficiencies of the commercially available photovoltaic systems are still low such as $14-20 \%$ for silicon solar cells and 25 $30 \%$ for III-V multi-junction solar cells [5]. The concentration of solar radiations on photovoltaic cells can enable the replacement of expensive photovoltaic area with less expensive concentrating mirrors or lenses thereby providing electricity at a reduced cost [6]. Although the electricity generation per unit area of a concentrated photovoltaic (CPV) is greater than that of the non-concentrated PV, the increase in temperature of the solar cells due to increased solar radiations after concentration leads to reduced efficiency and cell degradation [7]. Therefore, effective thermal management of concentrated photovoltaic systems is essential to improve its conversion efficiency and increase its life span $[8,9]$.

Research on photovoltaic thermal management with the use of thermoelectric devices has grown exponentially recently. A thermoelectric device is a bidirectional energy converter that can convert thermal energy directly into electricity via the Seebeck effect [10] while the reverse phenomenon is called Peltier effect by which electricity is converted to thermal energy [11]. A thermoelectric generator (TEG) operates based on the Seebeck effect while a thermoelectric cooler operates based on the Peltier effect. The advantages of a thermoelectric generator include solid-state operation, gas-free emission, vast scalability, maintenance-free operation, clean energy production, long life-span and high reliability [12]. However, the low conversion efficiency and high material cost of the thermoelectric generator are the two main factors limiting its wide spread application [13]. The performance of a thermoelectric material is usually determined by a dimensionless parameter call figure of merit (ZT) which is expressed as $\frac{\alpha^{2} T \sigma}{\kappa}$. Where $\alpha$ is the Seebeck coefficient, $T$ is temperature, $\sigma$ is electrical conductivity and $\kappa$ is thermal conductivity. Therefore, a high figure of merit value provides a high thermal efficiency for the thermoelectric generator [14]. Asides improving the ZT of materials, geometry optimisation is another effective method to optimise the performance of TEGs [15].

Furthermore, an alternative optimisation method is the hybridization of thermoelectric generators. Consequently, one of the research directions being explored recently is the integration of thermoelectric generators into photovoltaic systems for enhanced overall performance. Combining a photovoltaic module and thermoelectric generator will allow the use of wider solar spectrum as the photovoltaic utilizes the ultraviolent and visible regions of the solar spectrum while the thermoelectric utilizes the infrared region. The addition of a thermoelectric generator directly behind the photovoltaic module will allow the utilization of the PV waste heat for additional electricity generation while simultaneously lowering the PV temperature thereby, resulting in an enhanced hybrid system overall performance [16]. The integration of photovoltaic and thermoelectric generator requires special attention because the photovoltaic and the thermoelectric generator have an opposite relationship with temperature. While the PV requires low temperature to achieve high efficiency, the TEG's conversion efficiency depends on achieving high temperature difference. Therefore, several researchers have paid attention to the effective integration of photovoltaic-thermoelectric (PV-TE). Two main integration approaches have been researched extensively for a PV-TE including direct coupling [17] and spectrum splitting [18]. The difference between the two approaches is the absence or presence of a beam splitter:

Kraemer et al. [19] proposed a general optimisation technique using spectrum splitting integration approach for a hybrid PV-TE using different solar cells which operated at ambient temperature and different solar TEG designs. Results showed the strong influence of the solar cell spectral efficiency and solar TEG efficiency on the maximum hybrid system efficiency. Contrarily, van Sark [20] introduced the application of direct coupling approach for studying the feasibility of PV-TE modules in two different cities. Results obtained from the idealized model employed by the authors suggested that the efficiency of roof integrated PV- 
TE modules could be enhanced by $23 \%$ when typical ZT value of 1.2 is used. Similarly, Rezania et al. [21] presented a feasibility study for concentrated PV-TE system using a thermally coupled model. The economic viability of the hybrid system was evaluated using critical system parameters such as concentration ratio and heat transfer coefficient. Results showed that the power generation of the TEG in the hybrid system is significant at high sun concentrations. Furthermore, Ju et al. [22] presented a numerical and optimization study for a concentrated spectrum splitting PV-TE system. The thermal and electrical performance of a hybrid PV-TE system comprising of GaAs (Gallium arsenide) solar cell and Skutterudite $\mathrm{CoSb}_{3}$ (Cobalt antimony) solar TEG were studied and the results showed that cooling of the hybrid system is very essential and the TEG contributed about $10 \%$ of the overall power output of the hybrid system.

Passive cooling techniques have been applied to improve the performance of hybrid PV-TE systems. Rodrigo et al. [23] presented an integrated electrical, thermal and economic model for a concentrated PV-TE system which allowed the thermoelectric generator area to be adjusted. Results showed that the use of low thermal resistance heat sinks could enable the achievement of a maximum hybrid system efficiency of $39.2 \%$ at $800 x$ concentration factor. A novel photovoltaic-thermoelectric system with flat plate micro-channel heat pipe was presented by Li et al. [24,25]. A theoretical study was performed to analyse the hybrid system performance under different ambient conditions and results showed that the new PV-TE system provided a higher electrical output and economic performance compared to the conventional system. Similarly, Shittu et al. [26] recently presented a comparative three-dimensional study of a concentrated PVTE with and without flat plate heat pipe. The influence of key system parameters such as concentration ratio, ambient temperature, wind speed and TEG cold side temperature were analysed in detail and the results showed that the use of heat pipe is beneficial for PV-TE performance enhancement. Asides heat pipe, phase change material (PCM) has also been incorporated into PV-TE. Recently, Darkwa et al. [27] developed a numerical model to study the performance of a hybrid PV-TE with PCM and the model was validated by experimental results. The authors argued that thicker PCM layers are more effective in lowering the PV temperature for long periods. Similarly, Cui et al. [28] performed an experimental investigation of a concentrated PV-TE system with PCM. A comparison between the PV-TE-PCM and conventional PV system was made, and the results showed that interface thermal contact resistance and poor PCM thermal conductivity can cause high temperature variations in the PV cell, PCM and TEG which is not beneficial for the hybrid system performance.

Pounraj et al. [29] presented a detailed experimental study on a Peltier based hybrid photovoltaic/thermal (PV/T) active solar still. The function of the Peltier device in the hybrid system was to enhance the production of distilled water during the processes for evaporation and condensation. Results revealed that the new hybrid system provided an efficiency that was $30 \%$ higher than that of the conventional passive still. Furthermore, the hybrid system efficiency was higher than that of the actual solar PV system by 38\%. Tijani et al. [30] developed an automatic solar-powered domestic water cooling system which had multi-stage Peltier devices. The system was developed as a solution to the lasting problem of domestic hot water especially during summer climatic conditions in regions with little or no rain. Real time results showed that the laboratory prototype was an effective solution. Furthermore, Daghigh and Khaledian [31] presented an experimental and theoretical study on a solar thermoelectric cooling-heating system which used a photovoltaic collector under weather conditions in Iran. It was found that the hybrid system could be used to provide preheating support for domestic hot water and heating systems simultaneously. Similarly, He et al. [32] presented an experimental and theoretical study on a thermoelectric cooling and heating system which was driven by a heat pipe photovoltaic/thermal panel and operated in winter condition. They found that the PV/T panel electrical efficiency was $16.7 \%$ and thermal efficiency of the system was $23.5 \%$.

External load resistance attached to the thermoelectric generator significantly affects the power output of the TEG and the hybrid PV-TE. While it is generally agreed that for the thermoelectric generator alone can achieve its maximum power output when the load resistance is equal to the TEG internal resistance [33], such agreement is not applicable for the hybrid PV-TE system. In fact, Li et al. [34] argued that the thermoelectric load resistance for maximum power output of the TE alone and hybrid PV-TE is different. This finding was also echoed by Yin et al. [35] who found that the TE module achieved its highest power output at a different load resistance compared to that of the hybrid concentrated PV-TE system. Furthermore, they argued that the optimal performance of the hybrid CPVTE system could be achieved when the TE load resistance is slightly smaller than the optimum resistance for maximum TE power output. However, some studies do not agreed with this finding such as Lamba et al. [36] and Lin et al. [37] who both found that the optimum TE load resistance for the hybrid PV-TE is greater than the TE internal resistance. Therefore, it is imperative to investigate the optimum load resistance of the hybrid PV-TE and TE only with a detailed numerical model with reduced assumptions.

The thermoelectric thermal and electrical contact resistance are two important parameters that significantly influence the performance of the TEG. In fact, Ouyang et al. [38] argued that the thermoelectric electrical contact resistance in particular could significantly reduce the power output and efficiency of the TEG. In addition, the authors found that an increase in thermal contact resistance leads to an increase in the temperature distribution profile of the TEG. Wang et al. [39] experimentally studied the effects of thermal contact resistance on the performance of TEG. They found that the application of thermal grease to the contact interface enabled the decrease of the thermal contact resistance of the TEG thereby improving its performance. Furthermore, Kim et al. [40] presented a numerical model to analyse the performance of a TEG while considering its thermal and electrical contact resistance. The effect of thermoelectric leg height on the TEG performance in presence of thermal and electrical contact resistances were studied and results showed that the effect of the contact resistances become very significant when short thermoelectric legs are used, and they reduce the power output of the TEG. Zhang et al. [41] presented a theoretical analysis on the effect of contact resistance and thermoelectric geometry on the performance of annular thermoelectric generator (ATEG). They found that the increase in thermal and electrical contact resistance decreases the performance of the ATEG. Högblom et al. [42] performed a significant study on the effect of thermal and contact resistance on TEG performance using simulations and experiments. Results showed that ignoring the contact resistances in numerical simulations could lead to a significant over-prediction of the actual performance of the TEG. Bjørk [43] presented an analytical model to study the influence of thermal contact resistance on the efficiency of a TEG and found that the consideration of contact resistance allows for a more accurate prediction of the actual TEG performance.

Photovoltaic-thermoelectric thermal resistance optimization has been proposed as an effective method to improve the PV-TE performance [44]. Yin et al. [45] presented a detailed thermal resistance analysis for PV-TE performance optimization. Four types of PV cells were studied, and three cooling methods were compared. The impacts of the thermal resistances of the contact surface and TEG were studied using a one-dimensional numerical model. Results showed that the hybrid system performance could be improved significantly by increasing the thermal resistance of the thermoelectric generator. Furthermore, in a different study, the same authors found that decreasing the contact resistance can increase the temperature difference of the TEG and thermal grease is effective in 
suppressing the effect of thermal contact resistance [46]. Similarly, Zhang et al. [47] argued that the thermal contact resistance has a considerable influence on the PV-TE performance therefore, it should be reduced. In a subsequent work [48] the same authors investigated the effect of thermal resistances on the performance of highly concentrated PV-TE system. Two different cooling systems were investigated, and results showed that decreasing the thermal resistance between the TEG and heat sink should take more precedence than that of the PV and TE. Furthermore, Mahmoudinezhad et al. [49] studied the impact of thermal contact resistance on the performance of CPV-TE using a one-dimensional finite volume method. Results showed that the thermal contact resistance has a substantial effect on the performance of the hybrid system and should not be ignored.

Numerical simulations play a very significant role in research because they can help save costs and time while offering high accuracy [50,51]. In fact, threedimensional studies using finite element method in particular allow for detailed investigation and optimization activities to be carried out with high accuracy while also providing a user-friendly interface [52,53]. Mahmoudinezhad et al. [54] carried out an experimental and numerical investigation using COMSOL Multiphysics software on the transient behaviour of a concentrated hybrid PV-TE. The authors argued that the TEG enabled the achievement of a stable overall hybrid system power output. Similarly, the optimum TE geometry in a hybrid PV-TE was investigated by Li et al. [55] using finite element method and COMSOL Multiphysics software. Results showed that the optimum TE geometry in a hybrid system is different from that of a TEG only. In addition, Fallan Kohan [56] presented a three-dimensional numerical study of a PV-TE system. The authors argued that effective cooling of the thermoelectric generator is essential for performance enhancement of the hybrid system.

The detailed literature review presented above shows that although there is a plethora of one-dimensional studies available on PV-TE, there are very few threedimensional studies currently available. In addition, the significance of thermoelectric thermal and electrical contact resistance on the performance of TEG have been shown however, they are usually ignored in most numerical simulations for hybrid PV-TE. Furthermore, the inconsistency in optimum TE load resistance results available in literature necessities the need for further investigation using a more detailed numerical model with little assumptions. Therefore, for the first time, this study presents a detailed three-dimensional numerical investigation of a hybrid concentrated photovoltaic-thermoelectric system with consideration of all contact resistances. The significance of this is that a more accurate model is provided which can predict the actual performance of the hybrid systems under high solar concentrations. Temperature dependent thermoelectric material properties are utilized and the numerical study is performed using COMSOL 5.4 Multiphysics software without any simplification or ignorance of Joule heating, Thomson heating and Peltier heating. The effect of thermoelectric thermal and electrical contact resistances, photovoltaic-thermoelectric generator contact resistance and thermoelectric generator-heat sink contact resistance on the concentrated PV-TE performance are studied in detail. In addition, a parametric study is performed to investigate the optimum thermoelectric leg height, load resistance, concentration ratio and convective heat transfer coefficient. The optimum load resistance of TE in hybrid PV-TE and TE only is also investigated. Furthermore, a comparison of the contact resistance effects on the concentrated PV-TE performance is presented and the most significant contact resistance is analysed. Finally, the overestimation percentage of the concentrated PV-TE efficiency and power output resulting from the neglect/use of specific contact resistance is presented to show the significance of these contact resistances. The remainder of this paper is organized as follows: Section 2 presents a detailed structure description and material selection, numerical model is presented in Section 3, results and discussion are shown in Section 4 and conclusions from this study are presented in Section 5 .

\section{Structure description and material selection}

A direct coupling approach is used in this study for the concentrated photovoltaic-thermoelectric system (CPV-TE). As shown in Fig. 1a, the thermoelectric generator is directly attached to the back of the photovoltaic (PV) module and a heat sink is coupled to the TEG for cooling. The five layers of the PV including glass, ethylene vinyl acetate (EVA) top layer, polycrystalline silicon cell, EVA bottom layer and tedlar polyester tedlar (TPT) are shown in Fig. 1b. The PV layers all have unique functions such as glass cover, which provides mechanical strength and rigidity with high transmittance and low reflection. The solar cell is encapsulated between the two layers of the EVA and it is used to achieve the photovoltaic effect by which electricity is generated from solar radiation. Thus, the EVA provides adhesion between the solar cell, the glass layer and the back TPT layer. Lastly, the TPT provides durability and reliability for the PV module under extremely weather conditions. All the layers of the PV are of equal dimensions and in direct contact. Furthermore, the thermoelectric generator (TEG) is made up of a ceramic top and bottom layer which provides thermal conductivity, copper electrode which provides electrical connection and semiconductor thermoelectric materials (p-type and n-type) as shown in Fig. 1c. An external load resistance is connected across the terminals of the TEG to obtain its power output and the thermoelectric legs are of equal dimension. Convective cooling is used in this study therefore; copper heat sink with fins is attached to the cold side of the thermoelectric generator. The location of the first thermal contact between the PV back sheet (TPT) and the TEG top surface (ceramic) is shown in Fig. 1b. The second thermal contact between the TEG bottom surface (ceramic) and the heat sink is also shown in Fig. 1b. Furthermore, Fig. 1c shows the locations of the top side and bottom side thermoelectric thermal and electrical contacts. Therefore, in this study, the effect of four different contact resistances are investigated including thermal contact resistance between PV back surface and TEG top surface $\left(R_{p v_{-} e}\right)$, thermal contact resistance between TEG bottom surface and heat sink $\left(R_{\text {teg } \_ \text {sink }}\right)$, thermoelectric thermal contact resistance $\left(R_{c}\right)$ and electrical contact resistance $\left(R_{\text {cont }}\right)$. 


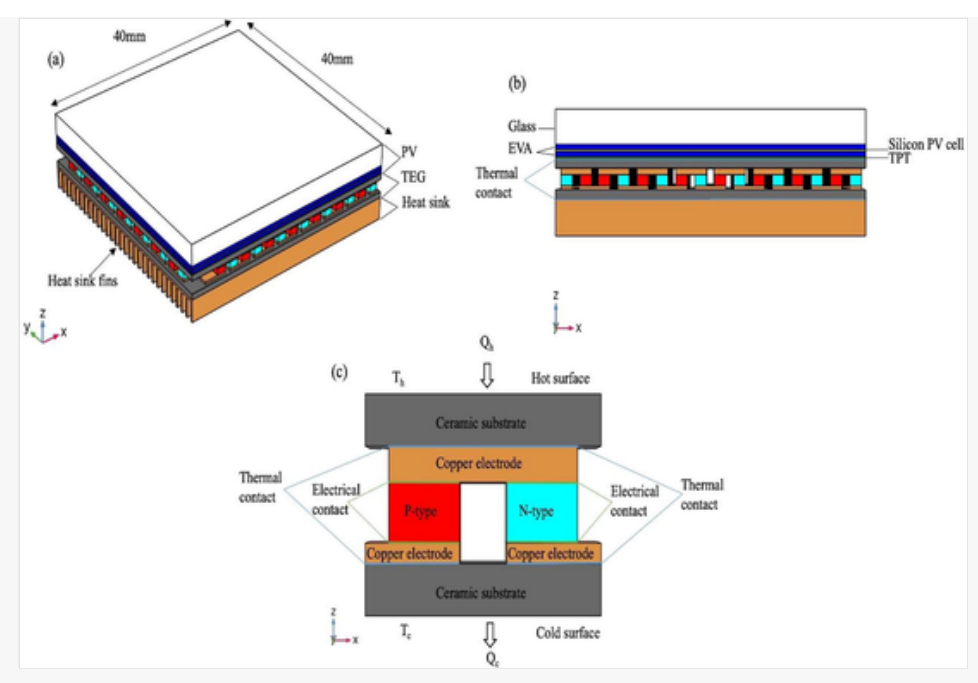

Schematic diagram of (a) PV-TE three-dimensional view (b) PV-TE front view and (c) TE uni-couple.

\subsection{Material selection}

This study is carried out using commercial bismuth telluride $\left(\mathrm{Bi}_{2} \mathrm{Te}_{3}\right)$ TEG device manufactured by Thermonamic Co. (TEP1-1264-3.4). The TEG is $40 \mathrm{~mm} \times 40 \mathrm{~mm}$ in dimension and it consists of 126 pairs of p-type and n-type thermoelectric legs, which are connected, thermally in parallel and electrically in series. The geometric parameters of the hybrid system studied are listed in Table 1 [57]. Aluminium oxide is used as the ceramic material and a copper heat sink is used. For low-range temperature operations $(<500 \mathrm{~K})$, bismuth telluride $\left(\mathrm{Bi}_{2} \mathrm{Te}_{3}\right)$ is the best performing TE material therefore, it is used. Temperature dependent $\mathrm{Bi}_{2} \mathrm{Te}_{3}$ materials are employed in this study which are expressed as polynomial functions shown in Table 2 [57]. The optical properties of the polycrystalline PV layers considered in this study are shown in Table 3 [58] and the remaining material properties used in this study are shown in Table 4.

\section{Table 1}

(i) The presentation of Tables and the formatting of text in the online proof do not match the final output, though the data is the same. To preview the actual presentation, view the Proof.

Hybrid system geometric parameters and properties.

\begin{tabular}{|c|c|c|c|}
\hline Parameter & Base value & Parametric value & Reference \\
\hline \multicolumn{4}{|l|}{ Photovoltaic } \\
\hline Area & $40 \mathrm{~mm} \times 40 \mathrm{~mm}$ & & {$[26]$} \\
\hline Glass thickness & $3.2 \mathrm{~mm}$ & & {$[58]$} \\
\hline EVA thickness & $4.6 \times 10^{-1} \mathrm{~mm}$ & & {$[58]$} \\
\hline Polycrystalline silicon thickness & $1.8 \times 10^{-1} \mathrm{~mm}$ & & {$[58]$} \\
\hline Tedlar polyester tedlar thickness & $1.8 \times 10^{-1} \mathrm{~mm}$ & & {$[58]$} \\
\hline \multicolumn{4}{|l|}{ Thermoelectric generator } \\
\hline Area & $40 \mathrm{~mm} \times 40 \mathrm{~mm}$ & & {$[57]$} \\
\hline Leg area & $1.5 \mathrm{~mm} \times 1.5 \mathrm{~mm}$ & & {$[57]$} \\
\hline Leg height & $1 \mathrm{~mm}$ & $1 \mathrm{~mm}-8 \mathrm{~mm}$ & {$[26]$} \\
\hline Upper copper thickness & $0.6 \mathrm{~mm}$ & & {$[57]$} \\
\hline Lower copper thickness & $0.34 \mathrm{~mm}$ & & {$[57]$} \\
\hline Ceramic thickness & $0.86 \mathrm{~mm}$ & & {$[57]$} \\
\hline \multicolumn{4}{|l|}{ Heat sink } \\
\hline Area & $40 \mathrm{~mm} \times 40 \mathrm{~mm}$ & & \\
\hline Height & $3.34 \mathrm{~mm}$ & & \\
\hline Number of fins & 30 & $5-40$ & \\
\hline
\end{tabular}




\section{Table 2}

(i) The presentation of Tables and the formatting of text in the online proof do not match the final output, though the data is the same. To preview the actual presentation, view the Proof.

Polynomial functions for thermoelectric material [57].

\begin{tabular}{|l|l|l|}
\hline Property & p-type polynomial expression & n-type polynomial expression \\
\hline $\begin{array}{l}\text { Seebeck } \\
\text { coefficient }(V / K)\end{array}$ & $-2.24407 \times 10^{-11} T^{3}+2.22834 \times 10^{-8} T^{2}-7.301 \times 10^{-6} T+1.023698 \times 10^{-3}$ & $1.68178 \times 10^{-11} T^{3}-1.77163 \times 10^{-8} T^{2}+6.203 \times 10^{-6} T-9.54589 \times 10^{-4}$ \\
\hline $\begin{array}{l}\text { Thermal } \\
\text { conductivity }\end{array}$ & $-5.82609 \times 10^{-8} T^{3}+1.03491 \times 10^{-4} T^{2}-0.05011 T+8.726$ & $3.76869 \times 10^{-9} T^{3}+2.81722 \times 10^{-5} T^{2}-0.02057 T+5.09531$ \\
\hline $\begin{array}{l}(W / m \bullet K) \\
\text { Electrical } \\
\text { resistivity }\left(\Omega \bullet \mathrm{m}^{2}\right)\end{array}$ & $-7.75456 \times 10^{-13} T^{3}+7.77051 \times 10^{-10} T^{2}-0.01853 \times 10^{-5} T+1.60117 \times 10^{-5}$ & $-6.04782 \times 10^{-13} T^{3}+6.09155 \times 10^{-10} T^{2}-1.715 \times 10^{-7} T+2.11951 \times 10^{-5}$ \\
\hline
\end{tabular}

\section{Table 3}

(i) The presentation of Tables and the formatting of text in the online proof do not match the final output, though the data is the same. To preview the actual presentation, view the Proof.

Photovoltaic optical material properties [58].

\begin{tabular}{|l|l|l|l|}
\hline Material & Reflectivity & Absorptivity & Transmissivity \\
\hline Glass & $4.00 \times 10^{-2}$ & $4.00 \times 10^{-2}$ & $9.20 \times 10^{-1}$ \\
\hline EVA & $2.00 \times 10^{-2}$ & $8.00 \times 10^{-2}$ & $9.00 \times 10^{-1}$ \\
\hline Polycrystalline silicon & $8.00 \times 10^{-2}$ & $9.00 \times 10^{-1}$ & $2.00 \times 10^{-2}$ \\
\hline TPT & $8.60 \times 10^{-1}$ & $1.28 \times 10^{-1}$ & $1.20 \times 10^{-2}$ \\
\hline
\end{tabular}

\section{Table 4}

(i) The presentation of Tables and the formatting of text in the online proof do not match the final output, though the data is the same. To preview the actual presentation, view the Proof.

Other material properties considered [26,52,57,58].

\begin{tabular}{|l|l|l|l|l|l|l|}
\hline & Heat capacity, $C_{p}(J / k g \cdot K)$ & Density, $\rho\left(\frac{k}{m^{3}}\right)$ & Seebeck coefficient, $\alpha(V / K)$ & Electrical conductivity, $\sigma(S / m)$ & Thermal conductivity, $\kappa(W / m \bullet K)$ & Emissivity \\
\hline Glass & $5 \times 10^{2}$ & $2.45 \times 10^{3}$ & - & - & 2.00 \\
\hline EVA & $2.09 \times 10^{3}$ & $9.60 \times 10^{2}$ & - & - & $3.11 \times 10^{-1}$ \\
\hline Silicon & $2.09 \times 10^{3}$ & $2.33 \times 10^{3}$ & - & - & $1.30 \times 10^{2}$ \\
\hline
\end{tabular}




\begin{tabular}{|c|c|c|c|c|c|c|}
\hline TPT & $1.25 \times 10^{3}$ & $1.20 \times 10^{3}$ & - & - & $1.50 \times 10^{-1}$ & 0.92 \\
\hline Ceramic & 900 & 3900 & - & - & 36 & 0.9 \\
\hline $\mathrm{Bi}_{2} \mathrm{Te}_{3}$ & 154 & 7700 & $\alpha(T)$ Table 2 & $\sigma(T)$ Table 2 & $\kappa(T)$ Table 2 & \\
\hline Copper & 385 & 8960 & - & $58,100,000$ & 238 & 0.07 \\
\hline
\end{tabular}

\subsection{System operation}

The hybrid system is thermally and directly coupled therefore; the input heat flux for the TEG is obtained directly from the back sheet of the PV. Solar radiation is concentrated on the top surface of the glass using typical Fresnel lens and this radiation is transmitted through the different layers of the PV. The polycrystalline silicon layer converts the radiation into electricity while the remaining unused heat is transmitted through the tedlar to the TEG. The heat sink attached to the TEG cold side helps to maintain a temperature difference across the TEG, which is necessary for power production. The overall performance of the hybrid system is simply a combination of the PV and TEG performance in terms of power output and efficiency.

\section{Numerical model description}

The photovoltaic, thermoelectric generator and hybrid system models used in this numerical study are described below. The PV and TEG are firstly modelled separately before they are integrated to form the hybrid PV-TE system.

\subsection{Thermoelectric generator model}

The thermoelectric generator operation is governing by the following equations which are solved using finite element method [59]:

$$
\rho C_{p} \frac{\partial T}{\partial t}+\nabla \cdot \vec{q}=\dot{q}
$$

where $C_{p}$ is specific heat capacity, $\vec{q}$ is heat flux vector, $\rho$ is the density, $T$ is temperature and $\dot{q}$ is the heat generation rate per unit volume.

Electric charge continuity equation is expressed as [60],

$$
\nabla \cdot\left(\vec{J}+\frac{\partial \vec{D}}{\partial t}\right)=0
$$

where $\vec{D}$ is the electric flux density vector and $\vec{J}$ is the electric current density vector.

The following thermoelectric constitutive equations are used to couple the Eqs. (1) and (2) [61],

$$
\vec{q}=T[\alpha] \cdot \vec{J}-[\kappa] \cdot \nabla T
$$

$\vec{J}=[\sigma] \cdot(\vec{E}-[\alpha] \cdot \nabla T)$

where $[\kappa]$ is the thermal conductivity matrix, $[\alpha]$ is the Seebeck coefficient matrix, and $[\sigma]$ is the electrical conductivity matrix.

$$
\vec{E}=-\nabla \varphi
$$

where $\varphi$ is the electric scalar potential and $\vec{E}$ is the electric field intensity vector.

The combination of the above equations results in the coupled thermoelectric equations which are expressed as,

$$
\rho_{d} C_{p} \frac{\partial T}{\partial t}+\nabla \cdot(T[\alpha] \cdot \vec{J})-\nabla \cdot([\alpha] \cdot \nabla T)=\dot{q}
$$

$\nabla \cdot\left([\varepsilon] \cdot \nabla \frac{\partial \varphi}{\partial t}\right)+\nabla \cdot([\sigma] \cdot[\alpha] \cdot \nabla T)+\nabla \cdot([\sigma] \cdot \nabla \varphi)=0$ 
where $[\varepsilon]$ represents the dielectric permittivity matrix.

Rewriting equations (6) and (7) results in [62],

$$
\nabla \cdot(T \alpha \vec{J})-\nabla \cdot(\lambda \nabla T)=\dot{q}
$$

$$
\nabla \cdot(\sigma \alpha \nabla \mathrm{T})+\nabla \cdot(\sigma \nabla \varphi)=0
$$

The thermoelectric generator electrical performance (power output and efficiency) are derived from the equations below [13]:

$$
V_{O C}=\alpha \Delta T
$$

where $\alpha$ is the Seebeck coefficient, $V_{O C}$ is the open circuit voltage, and $\Delta T$ is the temperature difference between the hot and cold sides of the TEG.

$$
V_{L}=V_{O C}-R_{i n} I=R_{L} I
$$

where $R_{i n}$ is the TEG internal resistance, $V_{L}$ is the output load voltage, and $I$ is the TEG current which is expressed as,

$$
I=\frac{V_{O C}}{R_{i n}+R_{L}}
$$

The thermoelectric generator power output is expressed as,

$$
P_{\text {teg }}=V_{L} I=R_{L} I^{2}
$$

The efficiency of the thermoelectric generator is given as,

$$
\eta_{\text {teg }}=\frac{P_{\text {teg }}}{Q_{h}}
$$

where $Q_{h}$ is the input power at the top surface of the TEG and $\eta_{\text {teg }}$ is the thermoelectric generator efficiency.

\subsection{Photovoltaic model}

The governing equations for the photovoltaic layers are given as [56]:

$$
\rho C_{p} \frac{\partial T}{\partial t}-\nabla \cdot(\kappa \nabla T)=q_{s o l}-P_{g e n}
$$

where $C_{p}, \kappa$ and $\rho$ are the specific heat capacity, thermal conductivity and density of each layer. $T$ is the temperature, $q_{s o l}$ is the volumetric solar energy absorption and $P_{\text {gen }}$ is the power generation per volume and this value is considered zero for all layers of the PV excluding the polycrystalline silicon cell layer.

The volumetric solar energy absorption in each layer is modelled as an internal heat generation and it is expressed as,

$q_{s o l, i}=\frac{G_{r e c, i} \times \alpha_{i} \times A_{i} \times C}{V_{i}}$ 
$G_{r e c, i}=G_{r e c, i-1} \times\left[\left(1-\alpha_{i-1}\right)-\rho_{i-1}\right]$

where $\alpha_{i}, V_{i}$, and $\rho_{i}$ are the absorptivity, volume and reflectivity of the ith layer respectively. $q_{s o l i}$ represents the volumetric solar energy absorption at each layer, $C$ is solar concentration ratio, $A_{i}$ represents the area of the ith layer and $G_{r e, i}$ is the solar radiation intensity at each layer. The reference irradiance $\left(G_{0}\right)$ used throughout this study is $1000 \mathrm{~W} / \mathrm{m}^{2}$.

In the polycrystalline silicon cell layer, power generation is considered as an internal heat sink and is given as [63]:

$$
\eta_{p v}=\eta_{r e f}\left[1-\beta\left(T_{p v}-T_{r e f}\right)\right]
$$

$P_{g e n}=q_{s o l, 3} \times \eta_{p v}$

where $\beta$ is the temperature coefficient, $\eta_{r e f}$ is the reference efficiency, $T_{p v}$ is the polycrystalline silicon layer average temperature, $T_{r e f}$ is the reference temperature of $298.15 \mathrm{~K}, q_{s o l, 3}$ is the volumetric solar energy absorption at the silicon layer and $\eta_{p v}$ is the PV efficiency.

The power generation obtained from Eq. (19) is determined by the temperature distribution in each PV layer therefore, finite element method is used to solve the coupled thermal and electrical Eqs. (15)-(19) simultaneously.

\subsection{Hybrid photovoltaic-thermoelectric model}

The overall hybrid system power output is a combination of the photovoltaic and thermoelectric individual power outputs expressed as,

$$
P_{p v-t e}=P_{g e n}+P_{t e g}
$$

Likewise, combining the photovoltaic and thermoelectric generator efficiencies provides the overall hybrid system efficiency expressed as,

$$
\eta_{p v-t e}=\eta_{p v}+\eta_{t e g}
$$

\subsection{Boundary conditions}

The boundary conditions considered in the thermoelectric generator model are listed below.

1. Steady state conditions are assumed throughout this study.

2. Adiabatic conditions are assumed on surfaces of the thermoelectric generator.

3. Fins are attached to completely cover the cold surface of the TEG and an equivalent convective heat transfer coefficient is used to model the heat transfer from the TEG to ambient.

4. Both the n-type and p-type leg coppers are connected to the different ends of an external load resistance.

The boundary conditions for photovoltaic model are as follows.

1. Convective and radiative heat loss are considered on the glass surface of the PV.

2. The initial temperature of the system is equal to the ambient temperature.

3. PV reference efficiency is $17 \%$ at $298.15 \mathrm{~K}$ reference temperature and temperature coefficient of $0.00451 / \mathrm{K}$ [58].

4. For radiative heat loss calculation, the glass surface of the PV is taken to view the sky.

At the glass surface of the PV, the radiative heat loss is calculated with the sky temperature expressed as [58]:

$$
T_{s k y}=T_{a}-6(K)
$$

where $T_{s k y}$ is temperature of sky and $T_{a}$ is temperature of ambient. 
where $h$ is the convective heat transfer coefficient $v$ is the wind speed $(\mathrm{m} / \mathrm{s})$.

Thermal contact resistance can be defined as a ratio between the interface temperature drop and the interface average heat flow expressed as [49],

$$
R_{c}=R_{p v_{-} \text {te }}=R_{\text {teg_h } \operatorname{sink}_{-}}=\frac{\Delta T_{\text {interface }}}{\dot{Q} / A}\left(m^{2} \cdot K / W\right)
$$

Interface heat transfer equation, which is given below, is used to evaluate the effect of thermal contact resistance between the thermoelectric copper-ceramic upper and lower interface, photovoltaic-thermoelectric generator interface and thermoelectric generator-heat sink interface.

$$
\dot{Q}=h_{c} A \Delta T_{\text {interface }}
$$

where $h_{c}$ is the thermal contact conductance which is simply the inverse of the thermal contact resistance and $\Delta T_{\text {interface }}$ is the effective temperature difference at the interface.

\subsection{Computation procedure}

The thermal and electrical contacts considered in this study are modelled as boundary conditions. The thermoelectric contact resistances are assumed the same on both sides of the p-type and n-type semiconductor materials and all the contact resistances values are assumed temperature independent. The magnitude of thermal and electrical contact resistance is considered over a wide range shown in Table 1, which have been obtained from referenced literatures. Furthermore, the thermal contact is implemented using COMSOL 5.4 Multiphysics thermal contact boundary feature under the heat transfer in solids interface. Equivalent thin resistive layer contact model is used, and the thermal contact resistance is provided. Furthermore, the surface emissivity of the upper and lower interface layers is provided as shown in Table 4. The electrical contact is implemented using the electrical contact boundary feature under the electric current interface. The constriction conductance is provided which is the inverse of the electrical contact resistance $\left(R_{\text {cont }}\right)$ and it is solved using the equation from COMSOL Multiphysics shown below.

$$
n \cdot J_{1}=h_{c o}\left(V_{1}-V_{2}\right)
$$

where $h_{c o}$ is the electrical contact conductance, $V_{1}-V_{2}$ is the interface voltage difference, $n$ is normal vector and $J_{1}$ is the current density.

\subsection{Model validation}

Two kinds of verifications are used to test the accuracy of the model. Firstly, a mesh convergence test is carried out to ensure the results are independent of the mesh size by using the in-built COMSOL Multiphysics mesh settings. Six different mesh element size are tested, and the results are shown in Table 5. The average PV cell temperature and the power output of the hybrid system are obtained and as can be seen in Table 5, they converge when the Normal mesh is used. Therefore, the Fine mesh is used for increased accuracy. Furthermore, the photovoltaic and thermoelectric generator models used in this study are validated with previous published works found in literature. The simulations conditions are reset to those in the referenced literatures and results are compared to test the accuracy of the models. The photovoltaic model is validated using a similar finite element model presented in [58] and the results are shown in Fig. 2a. In addition, the thermoelectric generator model is validated using a detailed TEG model which accounted for the thermoelectric thermal and electrical contact resistances presented in [57] and the results are shown in Fig. 2b.

Table 5

(i) The presentation of Tables and the formatting of text in the online proof do not match the final output, though the data is the same. To preview the actual presentation, view the Proof.

Mesh convergence test.

\begin{tabular}{|l|l|l|l|}
\hline Number of domain elements & Element size & Average PV cell temperature (K) & Hybrid power output (W) \\
\hline 27,177 & Extremely coarse & 397.66 & 1.4181 \\
\hline 41,137 & Extra coarse & 397.71 & 1.4174 \\
\hline 70,093 & Coarser & 397.74 & 1.4171 \\
\hline 132,759 & Coarse & 397.76 & 1.4169 \\
\hline
\end{tabular}




\begin{tabular}{|l|l|l|l|}
\hline 310,815 & Normal & 397.8 & 1.4166 \\
\hline 766,093 & Fine & 397.8 & 1.4166 \\
\hline
\end{tabular}

\section{Fig. 2}
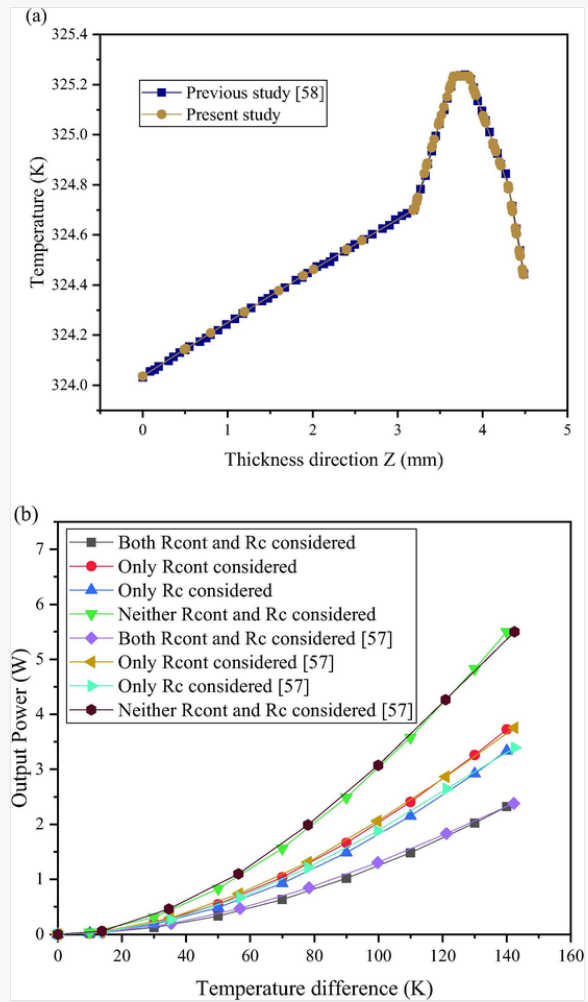

(a) PV model validation with [58] and (b) TEG model validation with [57].

Fig. 2a shows that the photovoltaic model used in this study agrees very well with the previous model developed in [58]. In addition, Fig. 2b shows that the thermoelectric generator model is also in good agreement with previous model developed in [57]. In addition, it can be seen from Fig. 2b that the thermal and electrical contact models used in this model are also accurate as the values obtained considering these contact resistances are in agreement with those reported in the referenced literature. Therefore, it is acceptable to say that the models used in this present study are accurate and justifiable.

\section{Results and discussion}

A detailed analysis of the results from this study is presented in this section and the results obtained are shown. Firstly, the selection of number of heat sink fins is presented, followed by the contact resistance study. Furthermore, a parametric optimization study is presented for the essential parameters influencing the performance of the hybrid system and finally a comparison of the contact resistance effects on the hybrid system performance is presented.

\subsection{Heat sink fins selection}

The number of fins present in a heat sink affects its heat removal capacity therefore, different number of fins are analysed to find the optimum value. As shown in Fig. 3a, the temperature of the PV cell, TE hot side and cold side all decrease as the number of fins increased. Consequently, the efficiency of the hybrid system, PV and TE all increase as shown in Fig. 3b. However, it can be seen clearly that the decrease in temperature and efficiency is no longer significant after 30 fins. Therefore, the number of fins used in the heat sink throughout this study is 30 . The base values shown in Table 1 are used to investigate the optimum number of heat sink fins. In addition, Fig. $3 b$ shows that the PV contributes the larger percentage of the overall efficiency of the hybrid system. The small difference between the TE hot and cold side temperature shown in Fig. 3a is the reason for its low efficiency as the performance of the TEG is highly dependent on the temperature difference across its surfaces. 

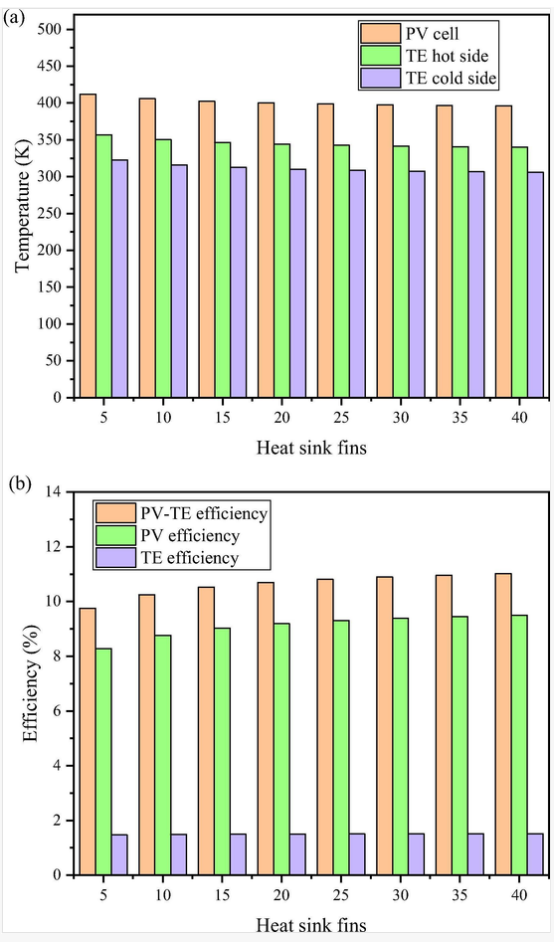

Variation of heat sink fins with (a) temperature and (b) efficiency.

\subsection{Contact resistance study}

Contact resistance between the interfaces of the hybrid system can significantly affect its performance therefore their effects are studied in this section. The effects of four different contact resistances are studied including, thermoelectric thermal contact resistance $\left(R_{c}\right)$, thermoelectric electrical contact resistance $\left(R_{\text {cont }}\right)$ , photovoltaic-thermoelectric interface thermal contact resistance $\left(R_{p v_{-} t e}\right)$ and thermoelectric generator-heat sink interface thermal contact resistance $\left(R_{\text {teg_ }} h_{s i n k}\right)$.

\subsubsection{Effect of thermoelectric thermal and electrical contact resistance}

The effect of the thermoelectric thermal contact resistance on the performance of the hybrid system is shown in Fig. 4. The base values are used for this study except the TE thermal contact resistance which is varied from 1E-6 to $1 \mathrm{E}-3 \mathrm{~m}^{2} \cdot \mathrm{K} / \mathrm{W}$ as reported in [38]. The TE thermal contact resistance is applied at the interface between the top and bottom electrical conductor and the top and bottom ceramic plates. It can be seen from Fig. 4a that the TE thermal contact affects the system performance as the efficiency and power output of the PV-TE, PV and TE all decrease when the contact resistance increased. In addition, an almost steady trend is noticed in Fig. $4 \mathrm{a}$ for low values of contact resistance however, as the value increases, a sharp decrease is noticeable therefore; the thermoelectric thermal contact resistance should be kept minimal. Thermal contact resistance results from surface roughness at the related interfaces and this leads to an increase in temperature as shown in Fig. 4b. Similar to the trend in Fig. 4a, the effect of the thermal contact is not that significant for low values however, once the TE thermal contact resistance attains a high value such as $1 \mathrm{E}-4 \mathrm{~m}^{2} \cdot K / W$ and upward, its drastic effect on the hybrid system performance becomes very clear. This is in agreement with the reported findings in [38]. In addition, Fig. 4 shows that there is an acceptable range (1E- $\left.6-1 \mathrm{E}-4 m^{2} \cdot K / W\right)$ of TE thermal contact resistance that have little influence on the hybrid system performance however, beyond this range, the concentrated PV-TE efficiency and power output decrease significantly. 

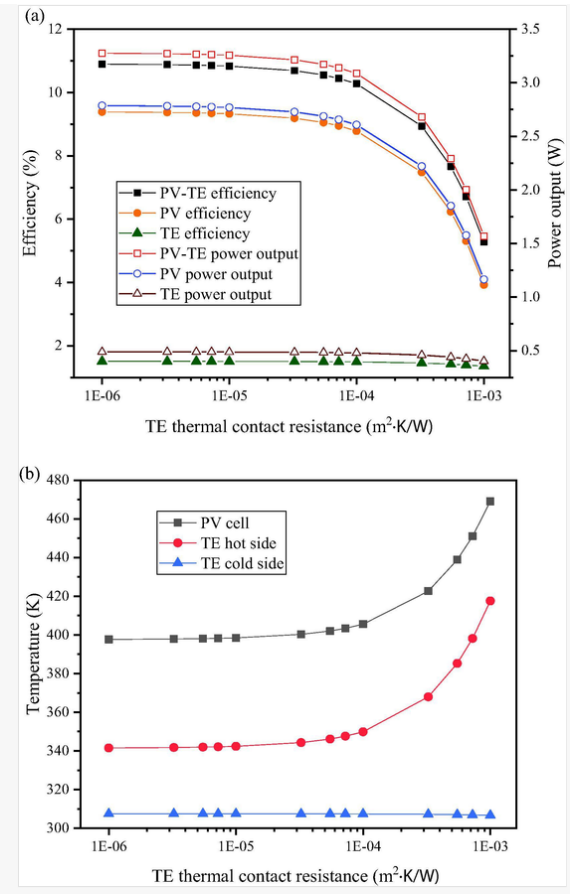

Relationship between TE thermal contact resistance and (a) efficiency, power output and (b) temperature.

Fig. 5 shows the effect of thermoelectric electrical contact resistance on concentrated PV-TE performance. The electrical contact resistance is varied from 1E-9 to $1 \mathrm{E}-6 \Omega \cdot \mathrm{m}^{2}$ which is an acceptable range obtained from [38] while other parameters are kept at base values shown in Table 1. The TE electrical contact is applied at the interface between the p-type, n-type legs and the top and bottom electrical conductor. It can be seen from Fig. 5a that the efficiency and power output of the hybrid system decrease as the electrical contact resistance increased. However, the decrease in performance becomes insignificant from $1 \mathrm{E}-7 \Omega \cdot \mathrm{m}^{2}$. The reason for this is shown in Fig. $5 \mathrm{~b}$ where it can be seen that the PV cell temperature increase and TE temperature difference reaches a plateau from 1E-7 $\Omega \cdot \mathrm{m}^{2}$ consequently, the performance of the hybrid system is no longer severely affected. The effect of contact resistance is more significant for short thermoelectric legs, which are used in this study. Furthermore, large values of electrical contact resistance allow a lower current density therefore, increase in electrical contact resistance leads to decrease in current flow and a subsequent decrease in power output and efficiency.

Fig. 5
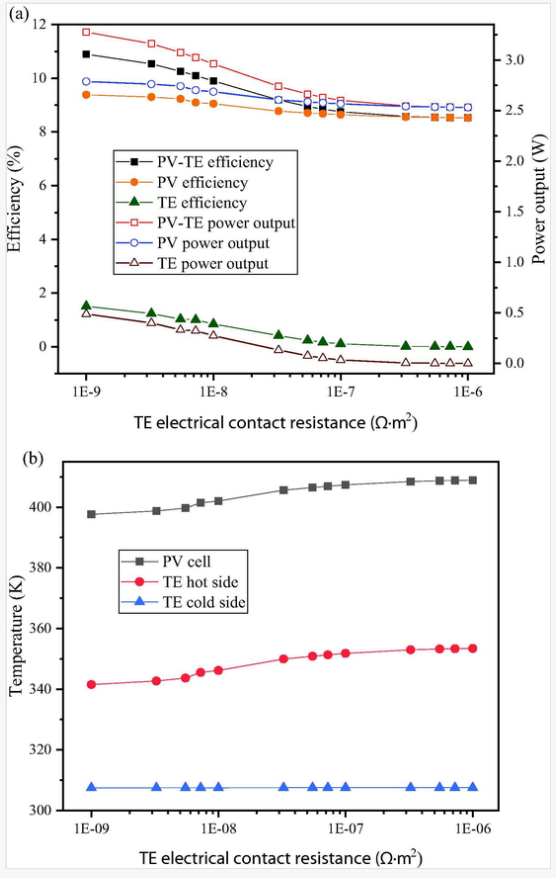

Effect of TE electrical contact resistance on (a) efficiency, power output and (b) temperature.

\subsubsection{Effect of coupling interface thermal contact resistance}


The effect of thermal contact resistance between the PV lower layer and the TEG top surface on the performance of the hybrid system is shown in Fig. 6. Base values of concentration ratio 30, convective heat transfer coefficient $500 \mathrm{~W} / \mathrm{m}^{2} \cdot \mathrm{K}$ and others shown in Table 1 are used while the thermal contact resistance between the PV and TEG $\left(R_{p v_{-} t e}\right)$ is varied from 0 to $1000 \mathrm{~mm}^{2} \cdot K / W$. As shown in Fig. 6a, the efficiency of the PV-TE, PV and TE all decrease as the thermal contact resistance increased. This is expected as the increase in thermal contact resistance leads to a decrease in heat transfer from the PV to the TEG and a subsequent increase in temperature as shown in Fig. 6b. The TEG heat removal capability from the PV is decreased as the thermal contact resistance increases. The efficiency of the hybrid system decreases by about $12.6 \%$ when $R_{p v_{-} t e}$ increases from 0 to $1000 \mathrm{~mm}^{2} \cdot \mathrm{K} / \mathrm{W}$. Therefore, it is imperative to reduce this contact resistance as low as possible in a hybrid system.

\section{Fig. 6}
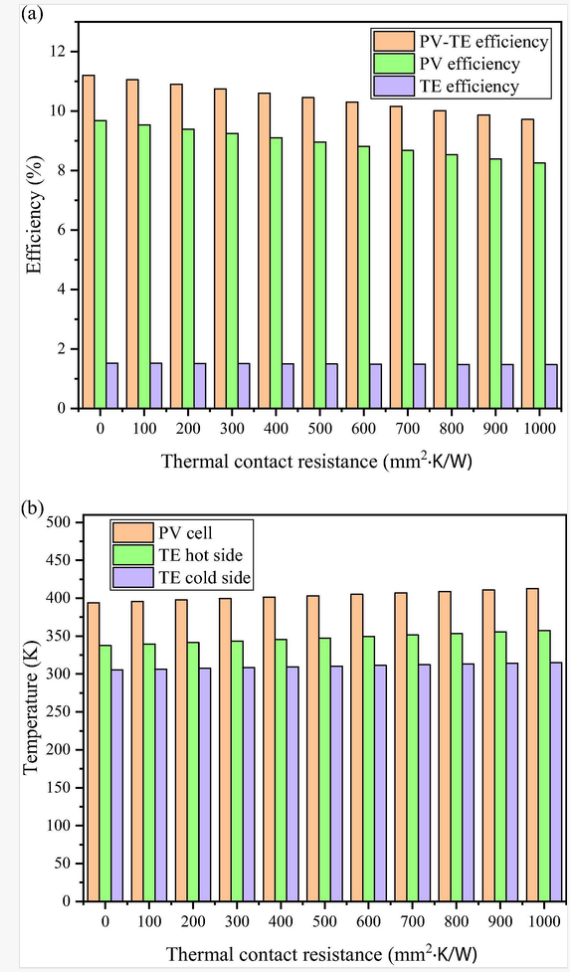

Relationship between PV-TE interface thermal contact resistance and (a) efficiency and (b) temperature.

Fig. 7 shows the variation of the hybrid system performance with the thermal contact resistance between the TEG and heat sink $\left(R_{\text {teg_hsink }}\right)$. A similar trend to the one observed in Fig. 6 is shown in Fig. 7 as the increase in thermal contact resistance between the TEG and heat sink reduces the cooling effectiveness of the heat sink. Since the performance of the TEG and the hybrid system is greatly affected by the temperature distribution in the system, Fig. 7a shows that the efficiency of the hybrid system will reduce as the thermal contact is increased. This reduction in efficiency is caused by the increase in temperature shown in Fig. 7b. The efficiency of the hybrid system decreases by about $13.23 \%$ when $R_{\text {teg_hsink }}$ increases from 0 to $1000 \mathrm{~mm} \mathrm{~m}^{2} \cdot \mathrm{K} / \mathrm{W}$. Figs. 6 and 7 show that the effect of the thermal contact resistances $\left(R_{p v_{-} t e}\right.$ and $\left.R_{\text {teg } h \text { sink }}\right)$ on the efficiency and power output of the hybrid system is not that significant at values less than $200 m m^{2} \cdot K / W$ therefore, there is no significant advantage to reducing the thermal contact resistance to $0 \mathrm{~mm}^{2} \cdot K / W$. This is in agreement with the reported findings in [47]. 

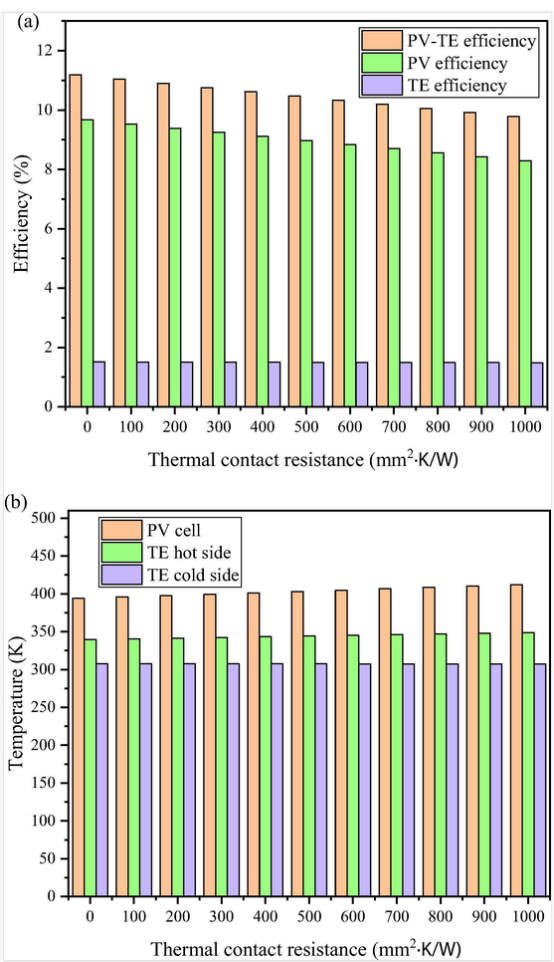

Variation of TEG-heat sink thermal contact resistance with (a) efficiency and (b) temperature.

A comparison between the effects of $R_{p v_{-} t e}$ and $R_{\text {teg } \_ \text {sink }}$ on the power output of the hybrid system and TE temperature difference is shown in Fig. 8. It can be seen clearly that the thermal contact resistance between the TEG and heat sink $\left(R_{\text {teg }}\right.$ hsink $)$ has a greater effect on the system performance compared to that between the PV and TE. Therefore, as shown in Fig. 8, decreasing $R_{\text {teg } \_ \text {sink }}$ should take precedence over $R_{p v_{-} t e}$ as it is more important.

\section{Fig. 8}

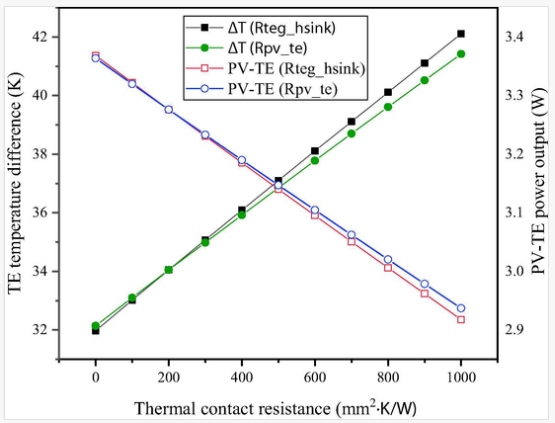

Comparison of PV-TE interface and TEG-heat sink thermal contact resistance effect.

\subsubsection{Three-dimensional temperature and voltage distributions}

The three-dimensional nature of this study allows valuable temperature and voltage distribution information to be obtained to better understand the performance of the hybrid system. The temperature and voltage distributions in the hybrid system using the base values are shown in Fig. $9 \mathrm{a}$ and $\mathrm{b}$ respectively. As expected, Fig. 9a shows that the PV has the highest temperature value since it is directly receiving the concentrated solar radiation while the TEG cold side has the lowest temperature value because of the convective cooling via heat sink. Fig. $9 \mathrm{~b}$ shows the voltage distribution through the total 252 legs of the thermoelectric generator. 

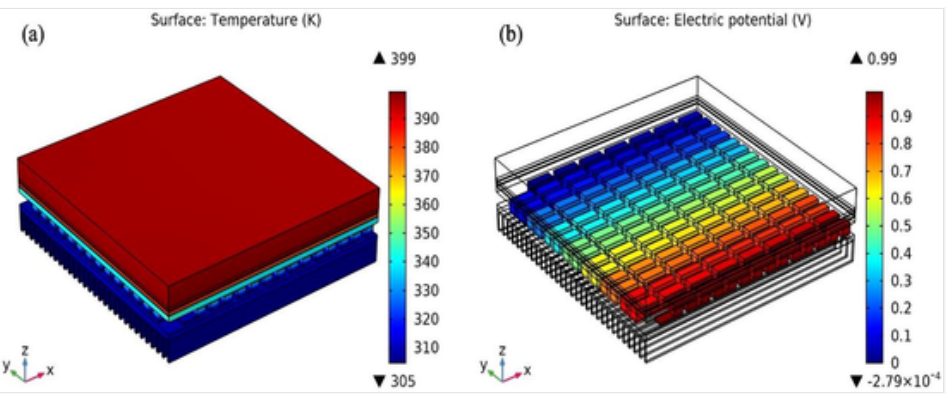

(a) Temperature and (b) voltage distribution for base values.

The distributions of temperature and voltage at the thermal and electrical contact interfaces in the thermoelectric generator are shown in Fig. 10. As shown in Fig. 10a and b, the temperature of the interface layers increases significantly when the TE thermal contact resistance increases from $1 \mathrm{E}-6$ to $1 \mathrm{E}-3 \mathrm{~m} \mathrm{~m}^{2} \cdot K / W$. This is the reason for the decrease in hybrid system performance observed in Fig. 9a. Furthermore, Fig. 10c and d show that the voltage at the electrical contact interface of the TEG decreases as the electrical contact resistance increases from $1 \mathrm{E}-9$ to $1 \mathrm{E}-6 \Omega \cdot \mathrm{m}^{2}$ consequently, the efficiency and power output of the hybrid system decrease as shown in Fig. 5a. The temperature distributions at the PV-TE and TEG-heat sink contact interfaces are shown in Fig. 11a and b respectively for the base values considered. The high values shown in Fig. 11a are because of the contact location, which is close to the PV where the most heat is generated while the lower values shown in Fig. 11b are because the contact location is at the TEG cold side.

Fig. 10
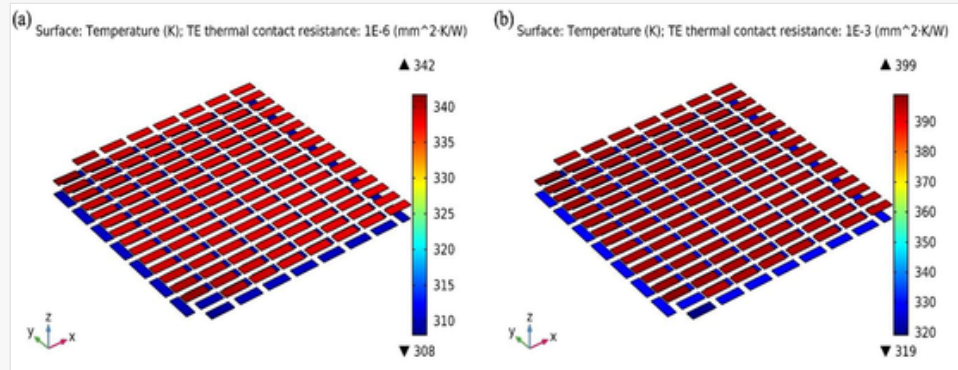

(c)

(d)

Surface: Electric potential (V): TE electrical contact resistance: $1 E-9\left(0 \cdot \mathrm{m}^{\wedge} 2\right)$

Surface: Electric potential (V): TE electrical contact resistance: $1 E-6\left(0-\mathrm{m}^{\wedge} 2\right)$
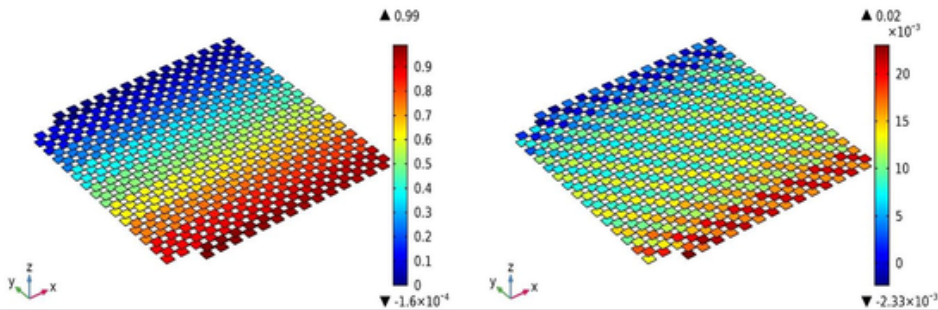

(a, b) Temperature distribution for TE thermal contact resistance interface and (c, d) voltage distribution for TE electrical contact resistance interface.

\section{Fig. 11}
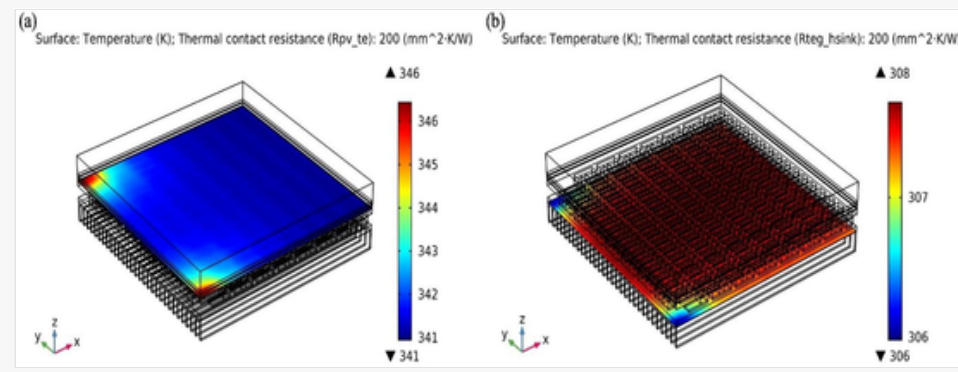

Temperature distribution for (a) PV-TE contact interface and (b) TEG-heat sink contact interface.

\subsection{Parametric optimization study}


Parameters such as thermoelectric leg height, external load resistance, concentration ratio and convective heat transfer coefficient significantly affect the performance of the concentrated PV-TE. Therefore, a parametric study is carried out to determine the optimum value for each of these parameters. This parametric study is carried out using the parametric values shown in Table 1 for the investigated parameters while the remaining parameters are kept at their base value.

\subsubsection{Effect of leg height and load resistance}

Fig. 12 shows the effect of thermoelectric leg height on the hybrid system performance. As can be seen in Fig. 12a, short thermoelectric legs provide the highest power output and efficiency for the hybrid system however; this is not the case for the TE in the PV-TE. This is because, as the leg height increases, the temperature of the PV and TE hot side increases as shown in Fig. 12b therefore, the power output and efficiency of the TE subsystem will increase. Since the PV greatly determines the performance of the hybrid system, short thermoelectric legs are necessary to improve the heat transfer in the legs and reduce the temperature of the PV. Fig. 12a shows that the hybrid system efficiency decreases by about $69 \%$ when the thermoelectric leg height increases from $1 \mathrm{~mm}$ to $8 \mathrm{~mm}$.

\section{Fig. 12}
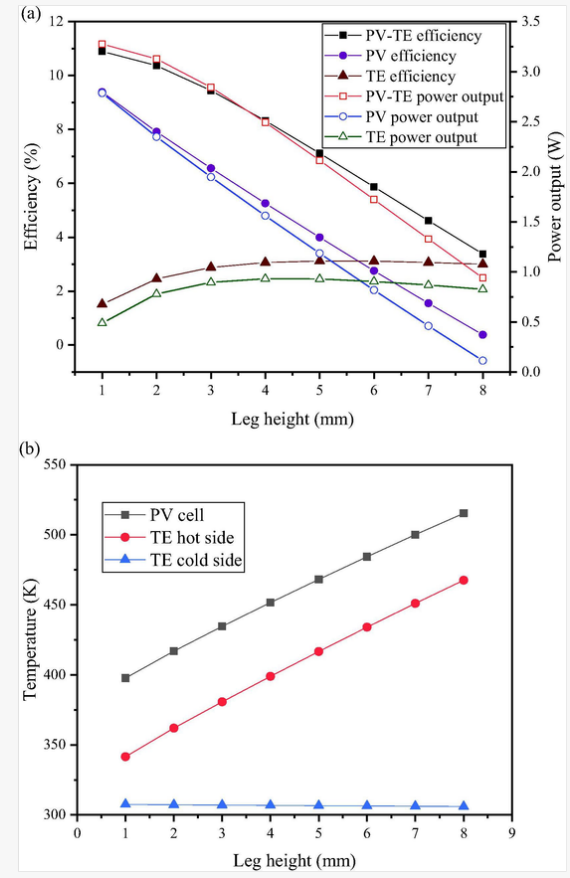

Variation of thermoelectric leg height with (a) efficiency, power output and (b) temperature.

Fig. 13 shows the effect of load resistance on performance of the hybrid PV-TE and a standalone TEG. This comparison is made to investigate the optimum thermoelectric load resistance for maximum power output and efficiency in a hybrid PV-TE and TEG only. It can be seen from Fig. 13a that the optimum TE load resistance is actually different for PV-TE and TE only. In fact, the maximum power output and efficiency of the hybrid system is obtained when the load resistance is $2 \Omega$ while that of the TE only is obtained when the load resistance is $3 \Omega$. Therefore, it can be concluded that the optimum TE load resistance in a hybrid PV-TE is lower than the TE internal resistance at which point the TE only attains its highest performance and this finding is in agreement with [35]. The temperature distribution in the hybrid system as load resistance is varied is shown in Fig. 13b. It can be seen from Fig. 13b that the increase in external load resistance leads to an increase in the PV cell temperature and thermoelectric temperature difference. The temperature increase experienced is because heat transfer in a thermoelectric generator depends on both heat conduction and Peltier effect of the thermoelectric legs. Consequently, as the external load resistance attached to the TEG is increased, the thermoelectric current is decreased thus; the quantity of thermal/heat energy transferred from the thermoelectric hot side to its cold side based on Peltier effect is reduced. 

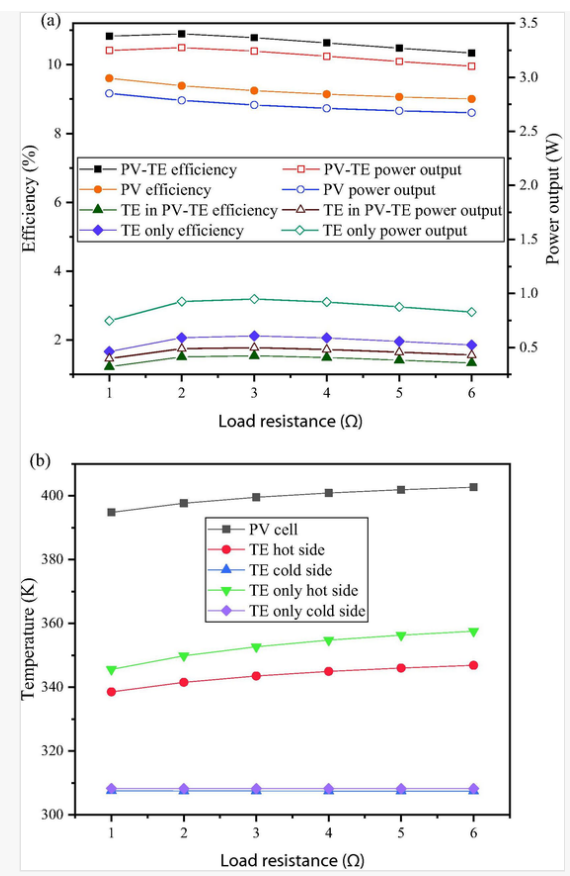

Effect of load resistance on (a) efficiency, power output and (b) temperature.

\subsubsection{Effect of concentration ratio and convective cooling}

Increase in concentration ratio implies an increase in solar radiation intensity on the surface of the PV. Fig. 14 shows the effect concentration ratio has on the efficiency, power output and temperature distribution in the hybrid system. As expected, Fig. 14a shows that an increase in concentration ratio leads to a significant decrease in PV-TE and PV efficiency. However, increase in concentration ratio leads to an increase in TE efficiency and power output. This is because, when the concentration ratio increases, the temperature of the PV rises significant as shown in Fig. 14b and this leads to an increase in the hot side temperature of the TEG resulting in a larger TE temperature difference and higher power output. Since all other parameters are kept constant at their base values except the concentration ratio, it can be seen from Fig. 14a that there exists an optimum concentration ratio for the hybrid PV-TE and PV at which maximum power output can be obtained. Increase in concentration ratio above this optimum value leads to a decrease in hybrid system performance because the TEG is no longer able to cool the PV and now acts as an additional thermal resistance.

\section{Fig. 14}
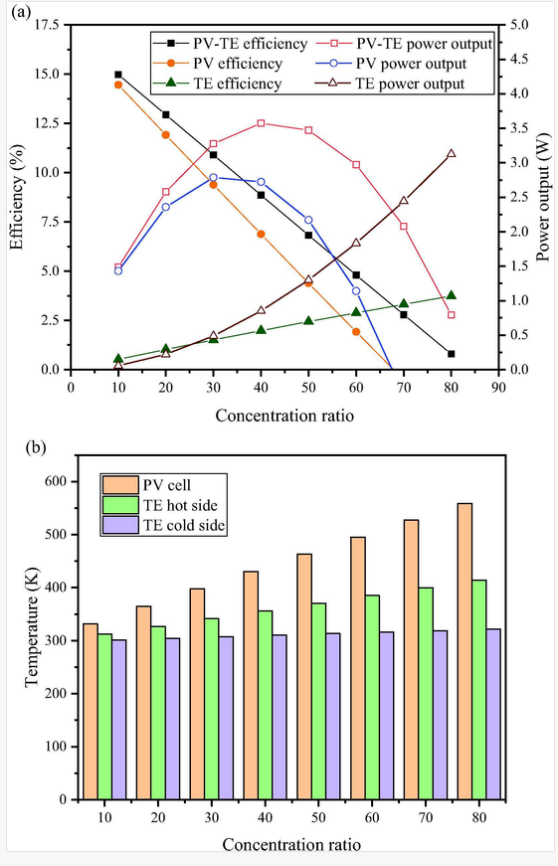

Effect of concentration ratio on (a) efficiency, power output and (b) temperature. 
Fig. 15 shows the significance of cooling system in a hybrid PV-TE. It can be seen from Fig. 15a that the hybrid system efficiency increases by about $20.6 \%$ when the convective heat transfer coefficient increases from 100 to $800 \mathrm{~W} / \mathrm{m}^{2} \cdot \mathrm{K}$. However, it is important to note that the efficiency enhancement achieved by the increase in heat transfer coefficient becomes insignificant at values above $400 \mathrm{~W} / \mathrm{m}^{2} \cdot \mathrm{K}$. This is because, the concentration ratio and other parameters are kept constant while varying only the heat transfer coefficient therefore, as shown in Fig. 15b, the reduction in PV cell temperature and TE hot side temperature become insignificant above $400 \mathrm{~W} / \mathrm{m}^{2} \cdot K$. Therefore, it can be concluded from Figs. 14 and 15 that the selection of appropriate values for concentration ratio and convective heat transfer coefficient is paramount for optimum hybrid system performance.

\section{Fig. 15}
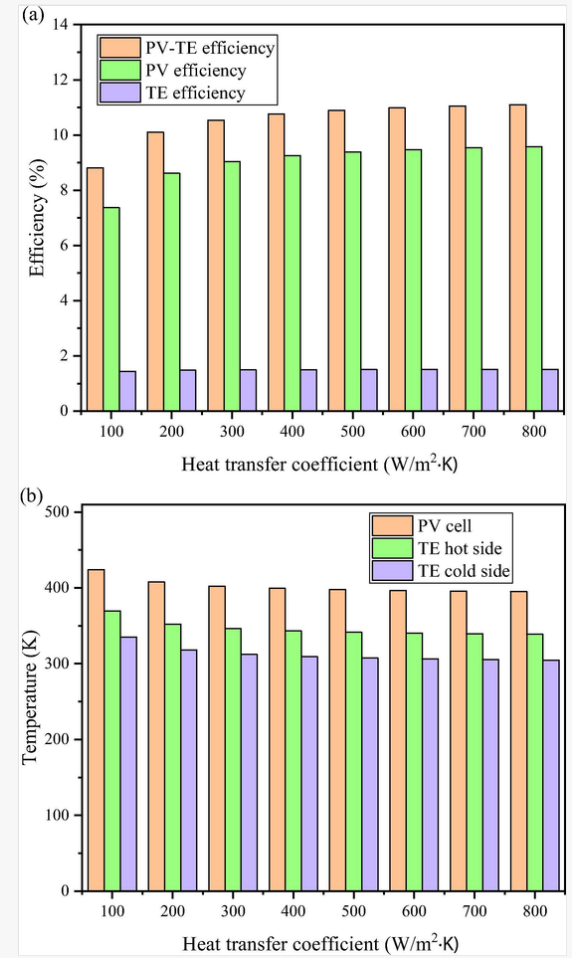

Variation of TEG cold side heat transfer coefficient with (a) efficiency and (b) temperature.

\subsection{Comparison of contact resistance effects}

This section is very important as is provides valuable insights into the significance of each contact resistance considered in this study. Twelve different cases are discussed in this section corresponding to different contact resistance scenarios as shown in Table 6. Since there are four contact resistances $\left(R_{c}, R_{\text {cont }}, R_{p v_{-} \text {te }}, R_{\text {teg_h } \text { sink }_{k}}\right)$ considered in this study, 12 combinations are possible which are explained in the sections below. When a specific contact resistance is not considered, that means perfect contact condition is assumed.

\section{Table 6}

(i) The presentation of Tables and the formatting of text in the online proof do not match the final output, though the data is the same. To preview the actual presentation, view the Proof.

Contact resistance case description.

\begin{tabular}{|l|l|}
\hline Case number & Description \\
\hline 1 & No contact resistance is considered. \\
\hline 2 & Only TE thermal contact resistance is ignored. \\
\hline 3 & Only TE electrical contact resistance is ignored. \\
\hline 4 & Only PV-TE interface thermal contact resistance is ignored. \\
\hline 5 & Only TEG-heat sink interface thermal contact resistance is ignored \\
\hline 6 & TE thermal and electrical contact resistances are ignored. \\
\hline 7 & PV-TE and TEG-heat sink thermal contact resistances are ignored. \\
\hline
\end{tabular}




\subsubsection{Different contact resistance case}

Firstly, the variation of hybrid system efficiency with different contact resistance case number is shown in Fig. 16a. It can be since clearly that when no contact resistance is considered (Case 1), the highest the hybrid system efficiency is obtained. This is expected as the presence of contact resistance of any kind reduces the efficiency of the hybrid system. In addition, it is obvious from Fig. 16a that the TE electrical contact resistance is more significant than the TE thermal contact resistance because the magnitude of efficiency decreases when each one is ignored is different. Case 2 implies that all other contact resistances are considered except the TE thermal contact resistance and since the efficiency is still as low as the efficiency for Case 12 where all contact resistance are considered, it can be concluded that the effect of the TE thermal contact resistance is not that significant. However, it is very important to note that this comparison is carried out using the base values. Furthermore, Fig. 16a shows that the TEG-heat sink interface thermal contact resistance is more important than the PV-TE interface resistance. In fact, it is the most important contact resistance that needs to be decreased. The same trend observed in hybrid system can be seen in the PV as shown in Fig. 16b. In addition, it can be seen that increase in convective heat transfer coefficient generally improves the efficiency of the system. Fig. 16c better explains the significance of thermoelectric thermal and electrical contact resistance. As can be seen from Fig. 16c, the thermoelectric electrical contact resistance is the most important contact resistance in the TEG. The trends shown in Fig. 16a and b are because of the temperature distribution in the system, which is shown in Fig. 16d. It can be seen from Fig. 16d that the increase in heat sink heat transfer coefficient leads to a significant decrease in the PV cell temperature. Consequently, effective cooling of the thermoelectric is essential for adequate thermal management of photovoltaic. Furthermore, it is clear that from Fig. 16d that the PV cell temperature in Case 1 is the lowest compared to all the other cases because the presence of contact resistance leads to an increase in temperature. This is the reason for the highest efficiency obtained for Case 1 shown in Fig. 16a. 

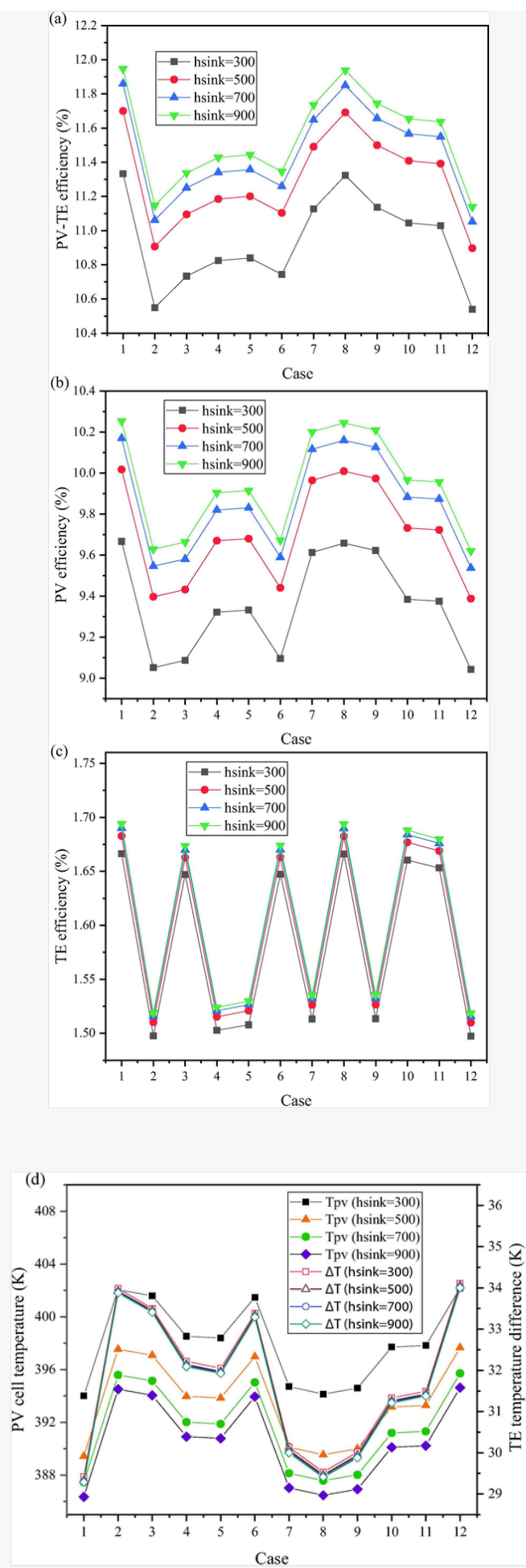

Effect of different contact resistance case with (a) PV-TE efficiency (b) PV efficiency (c) TE efficiency and (d) temperature.

\subsubsection{Overestimation calculation}

To quantify the effect of the contact resistances on the hybrid system performance, an overestimation calculation is made using the base values. Overestimation simply means the percentage increase in efficiency and power output resulting from ignoring one or more contact resistance. The percentage of overestimation is calculated using the equation below.

Overstimation $(\%)=\frac{\text { Specificcase value }- \text { Case } 12 \text { value }}{\text { Case } 12 \text { value }} \times 100$

Since contact resistances are essential parameters that need to be considered in any numerical study, the values obtained when all the contact resistances are considered (Case 12) is taken as the actual correct value. Therefore, the overestimation percentage is calculated only for Case 1 to Case 11 using the equation 

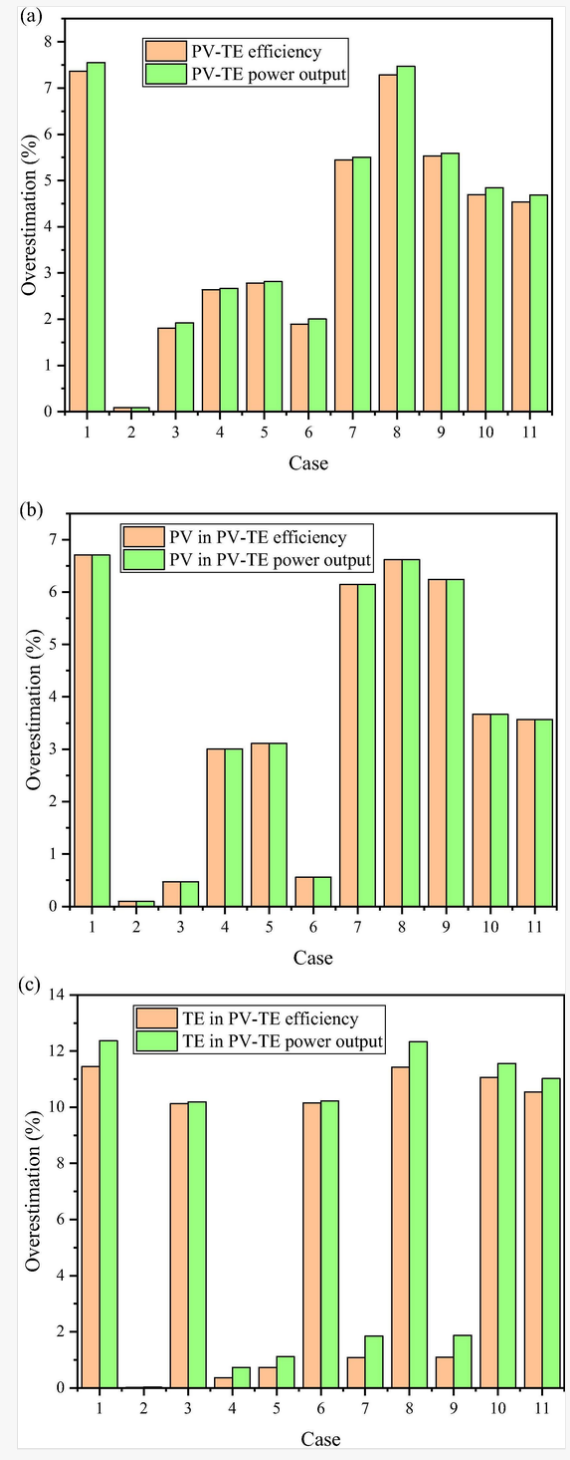

Overestimation calculation for (a) PV-TE (b) PV and (c) TE.

It can be seen from Fig. 17a that ignoring all contact resistances (Case 1) leads to an overestimation of the PV-TE power output and efficiency by about 7.6\% and $7.4 \%$ respectively. In addition, it can be seen that ignoring both the PV-TE interface and TEG-heat sink contact resistance causes an overestimation of PVTE power output and efficiency by $5.5 \%$ and $5.4 \%$ respectively. Furthermore, Fig. $17 \mathrm{~b}$ shows that the PV efficiency and power output are mainly affected by the PV-TE interface and TEG-heat sink thermal contact resistances. While Fig. 17c shows that the thermoelectric thermal and electrical contact resistances are the main resistances affecting the performance of the TEG. It is important to note that the overestimation calculation is specially based on the base values therefore, the use of parametric values listed in Table 1 will definitely alter the results and higher overestimation percentage could be obtained.

\section{Conclusion}

A comprehensive three-dimensional investigation on the effects of contact resistances on hybrid concentrated photovoltaic-thermoelectric performance has been carried out in this study. Furthermore, a parametric optimization study has been presented to enable better understanding of the effects of key parameters like thermoelectric leg height, load resistance, concentration ratio and heat sink convective heat transfer coefficient on the hybrid system performance. In addition, an exhaustive literature review was provided to enable quick understanding of the current works already performed in this area and to justify the importance of this present study. COMSOL 5.4 Multiphysics software was used to perform the numerical simulations and temperature dependent material properties were considered. In addition, four different contact resistances were studied and their effects on hybrid system perform were analysed in detailed. The main conclusions from this study are listed below.

1. Ignoring all contact resistances in the hybrid system leads to an overestimation of hybrid concentrated photovoltaic-thermoelectric power output and efficiency by about $7.6 \%$ and $7.4 \%$ respectively.

2. The optimum thermoelectric external load resistance in a hybrid concentrated photovoltaic-thermoelectric is different from that of the 
thermoelectric only.

3. The thermal contact resistance between the thermoelectric generator and heat sink, and that between the photovoltaic-thermoelectric interface are the most important contact resistances in the hybrid system that need to be reduced.

4. Hybrid system efficiency decreases by about $69 \%$ when thermoelectric leg height increases from $1 \mathrm{~mm}$ to $8 \mathrm{~mm}$ therefore, shorter legs are essential.

5. Efficient cooling of the thermoelectric generator leads to an efficiency increase of about $20.6 \%$ in the hybrid system when convective heat transfer coefficient increases from 100 to $800 \mathrm{~W} / \mathrm{m}^{2} \cdot K$.

6. The hybrid system efficiency decreased by $12.6 \%$ and $13.23 \%$ when the photovoltaic-thermoelectric interface thermal contact resistance and thermoelectric generator-heat sink thermal contact resistance increased from 0 to $1000 \mathrm{~mm}^{2} \cdot K / W$ respectively.

7. Increase in concentration ratio without subsequent increase in thermoelectric generator cooling capacity will lead to a sharp reduction in hybrid system power output after an initial performance enhancement.

\section{CRediT authorship contribution statement}

Samson Shittu: Conceptualization, Software, Writing - original draft. Guiqiang Li: Supervision, Project administration. Xudong Zhao: Funding acquisition. Xiaoli Ma: Writing - review \& editing. Yousef Golizadeh Akhlaghi: Formal analysis. Yi Fan: Visualization.

\section{Declaration of Competing Interest}

The authors declare that they have no known competing financial interests or personal relationships that could have appeared to influence the work reported in this paper.

\section{Acknowledgements}

This study was sponsored by the Project of EU Marie Curie International incoming Fellowships Program (745614). The authors would also like to express our appreciation for the financial supports from EPSRC (EP/R004684/1) and Innovate UK (TSB 70507-481546) for the Newton Fund - China-UK Research and Innovation Bridges Competition 2015 Project 'A High Efficiency, Low Cost and Building Integrate-able Solar Photovoltaic/Thermal (PV/T) system for Space Heating, Hot Water and Power Supply’ and DongGuan Innovation Research Team Program (No. 2014607101008).

\section{References}

The corrections made in this section will be reviewed and approved by journal production editor.

[1] Huen P, Daoud WA. Advances in hybrid solar photovoltaic and thermoelectric generators. Renew Sustain Energy Rev 2017;72:1295-1302. doi:10.1016/j.rser.2016.10.042.

[2] Akhlaghi YG, Zhao X, Shittu S, Badiei A, Cattaneo MEGV, Ma X. Statistical investigation of a dehumidification system performance using Gaussian process regression. Energy Build 2019;202:109406. doi:10.1016/j.enbuild.2019.109406.

[3] Xiao G, Zheng G, Qiu M, Li Q, Li D, Ni M. Thermionic energy conversion for concentrating solar power. Appl Energy 2017;208:1318-1342. doi:10.1016/j.apenergy.2017.09.021.

[4] Li G, Xuan Q, Pei G, Su Y, Ji J. Effect of non-uniform illumination and temperature distribution on concentrating solar cell - a review. Energy 2018;144:1119-1136. doi:10.1016/j.energy.2017.12.067.

[5] Ju X, Xu C, Hu Y, Han X, Wei G, Du X. A review on the development of photovoltaic/concentrated solar power (PV-CSP) hybrid systems. Sol Energy Mater Sol Cells 2017;161:305-327. doi:10.1016/j.solmat.2016.12.004.

[6] Royne A, Dey CJ, Mills DR. Cooling of photovoltaic cells under concentrated illumination: a critical review. Sol Energy Mater Sol Cells 2005;86:451-483. doi:10.1016/j.solmat.2004.09.003.

[7] Najafi H, Woodbury KA. Optimization of a cooling system based on Peltier effect for photovoltaic cells. Sol Energy 2013;91:152-160. doi:10.1016/j.solener.2013.01.026

[8] Shittu S, Li G, Akhlaghi YG, Ma X, Zhao X, Ayodele E. Advancements in thermoelectric generators for enhanced hybrid photovoltaic system performance. Renew Sustain Energy Rev 2019;109:24-54. doi:10.1016/j.rser.2019.04.023.

[9] Akhlaghi YG, Ma X, Zhao X, Shittu S, Li J. A statistical model for dew point air cooler based on the multiple polynomial regression approach. Energy 2019;181:868-881. doi:10.1016/j.energy.2019.05.213.

[10] Li G, Ma X, Shittu S, Zhao X. Solar thermoelectric technologies for power generation. In: Zhao X, Ma X, editors. Adv. Energy Effic. Technol. Sol. Heating, Cool. Power Gener.. Cham: Springer International Publishing; 2019. p. 341-371. doi: 10.1007/978-3-030-17283-1_10. 
[11] Shittu S, Li G, Zhao X, Ma X, Akhlaghi YG, Ayodele E. Optimized high performance thermoelectric generator with combined segmented and asymmetrical legs under pulsed heat input power. J Power Sources 2019;428:53-66. doi:10.1016/j.jpowsour.2019.04.099.

[12] He W, Zhang G, Zhang X, Ji J, Li G, Zhao X. Recent development and application of thermoelectric generator and cooler. Appl Energy 2015;143:1-25. doi:10.1016/j.apenergy.2014.12.075.

[13] Shittu S, Li G, Zhao X, Ma X, Akhlaghi YG, Ayodele E. High performance and thermal stress analysis of a segmented annular thermoelectric generator. Energy Convers Manag 2019;184:180-193. doi:10.1016/j.enconman.2019.01.064.

[14] He H, Wu Y, Liu W, Rong M, Fang Z, Tang X. Comprehensive modeling for geometric optimization of a thermoelectric generator module. Energy Convers Manag 2019;183:645-659. doi:10.1016/j.enconman.2018.12.087.

[15] Erturun U, Erermis K, Mossi K. Influence of leg sizing and spacing on power generation and thermal stresses of thermoelectric devices. Appl Energy 2015;159:19-27. doi:10.1016/j.apenergy.2015.08.112

[16] Li G, Shittu S, Diallo TMO, Yu M, Zhao X, Ji J. A review of solar photovoltaic-thermoelectric hybrid system for electricity generation. Energy 2018;158:41-58. doi:10.1016/j.energy.2018.06.021.

[17] Li G, Chen X, Jin Y. Analysis of the primary constraint conditions of an efficient photovoltaic-thermoelectric hybrid system. Energies 2017;10. doi:10.3390/en10010020.

[18] Narducci D, Bermel P, Lorenzi B, Wang N. Hybrid and fully thermoelectric solar harvesting. 1st ed. Switzerland: Springer International Publishing; 2018. doi: 10.1109/IPDPS.2006.1639640.

[19] Kraemer D, Hu L, Muto A, Chen X, Chen G, Chiesa M. Photovoltaic-thermoelectric hybrid systems: a general optimization methodology. Appl Phys Lett 2008;92. doi:10.1063/1.2947591.

[20] Van Sark W. Feasibility of photovoltaic - thermoelectric hybrid modules. Appl Energy 2011;88:2785-2790. doi:10.1016/j.apenergy.2011.02.008.

[21] Rezania A, Rosendahl LA. Feasibility and parametric evaluation of hybrid concentrated photovoltaic-thermoelectric system. Appl Energy 2017;187:380-389. doi:10.1016/j.apenergy.2016.11.064.

[22] Ju X, Wang Z, Flamant G, Li P, Zhao W. Numerical analysis and optimization of a spectrum splitting concentration photovoltaicthermoelectric hybrid system. Sol Energy 2012;86:1941-1954. doi:10.1016/j.solener.2012.02.024.

[23] Rodrigo PM, Valera A, Fernández EF, Almonacid FM. Performance and economic limits of passively cooled hybrid thermoelectric generatorconcentrator photovoltaic modules. Appl Energy 2019;238:1150-1162. doi:10.1016/J.APENERGY.2019.01.132.

[24] Li G, Zhao X, Ji J. Conceptual development of a novel photovoltaic-thermoelectric system and preliminary economic analysis. Energy Convers Manag 2016;126:935-943. doi:10.1016/j.enconman.2016.08.074.

[25] Li G, Shittu S, Zhao X, Ma X. Preliminary experiment on a novel photovoltaic-thermoelectric system in summer. Energy 2019;188:116041. doi:10.1016/j.energy.2019.116041.

[26] Shittu S, Li G, Zhao X, Akhlaghi YG, Ma X, Yu M. Comparative study of a concentrated photovoltaic-thermoelectric system with and without flat plate heat pipe. Energy Convers Manag 2019;193:1-14. doi:10.1016/j.enconman.2019.04.055.

[27] Darkwa J, Calautit J, Du D, Kokogianakis G. A numerical and experimental analysis of an integrated TEG-PCM power enhancement system for photovoltaic cells. Appl Energy 2019;248:688-701. doi:10.1016/j.apenergy.2019.04.147.

[28] Cui T, Xuan Y, Yin E, Li Q, Li D. Experimental investigation on potential of a concentrated photovoltaic-thermoelectric system with phase change materials. Energy 2017;122:94-102. doi:10.1016/j.energy.2017.01.087.

[29] Pounraj P, Prince Winston D, Kabeel AE, Praveen Kumar B, Manokar AM, Sathyamurthy R, et al. Experimental investigation on Peltier based hybrid PV/T active solar still for enhancing the overall performance. Energy Convers Manag 2018;168:371-381. doi:10.1016/j.enconman.2018.05.011.

[30] Tijani IB, Al Hamadi AAA, Al Naqbi KASS, Almarzooqi RIM, Al Rahbi NKSR. Development of an automatic solar-powered domestic water cooling system with multi-stage Peltier devices. Renew Energy 2018;128:416-431. doi:10.1016/j.renene.2018.05.042.

[31] Daghigh R, Khaledian Y. Effective design, theoretical and experimental assessment of a solar thermoelectric cooling-heating system. Sol Energy 2018;162:561-572. doi:10.1016/j.solener.2018.01.012.

[32] He W, Zhou J, Chen C, Ji J. Experimental study and performance analysis of a thermoelectric cooling and heating system driven by a photovoltaic/thermal system in summer and winter operation modes. Energy Convers Manag 2014;84:41-49. doi:10.1016/j.enconman.2014.04.019. 
[33] Li G, Ji J, Zhang G, He W, Chen X, Chen H. Performance analysis on a novel micro-channel heat pipe evacuated tube solar collectorincorporated thermoelectric generation. Int J Energy Res 2016;40:2117-2127. doi:10.1002/er.3589.

[34] Li G, Zhou K, Song Z, Zhao X, Ji J. Inconsistent phenomenon of thermoelectric load resistance for photovoltaic-thermoelectric module. Energy Convers Manag 2018;161:155-161. doi:10.1016/j.enconman.2018.01.079.

[35] Yin E, Li Q, Xuan Y. Experimental optimization of operating conditions for concentrating photovoltaic-thermoelectric hybrid system. J Power Sources 2019;422:25-32. doi:10.1016/j.jpowsour.2019.03.034.

[36] Lamba R, Kaushik SC. Solar driven concentrated photovoltaic-thermoelectric hybrid system: numerical analysis and optimization. Energy Convers Manag 2018;170:34-49. doi:10.1016/j.enconman.2018.05.048.

[37] Lin J, Liao T, Lin B. Performance analysis and load matching of a photovoltaic-thermoelectric hybrid system. Energy Convers Manag 2015;105:891-899. doi:10.1016/j.enconman.2015.08.054.

[38] Ouyang Z, Li D. Modelling of segmented high-performance thermoelectric generators with effects of thermal radiation, electrical and thermal contact resistances. Sci Rep 2016;6:1-12. doi:10.1038/srep24123.

[39] Wang S, Xie T, Xie H. Experimental study of the effects of the thermal contact resistance on the performance of thermoelectric generator. Appl Therm Eng 2018;130:847-853. doi:10.1016/j.applthermaleng.2017.11.036.

[40] Kim CN. Development of a numerical method for the performance analysis of thermoelectric generators with thermal and electric contact resistance. Appl Therm Eng 2018;130:408-417. doi:10.1016/j.applthermaleng.2017.10.158.

[41] Zhang AB, Wang BL, Pang DD, Chen JB, Wang J, Du JK. Influence of leg geometry configuration and contact resistance on the performance of annular thermoelectric generators. Energy Convers Manag 2018;166:337-342. doi:10.1016/j.enconman.2018.04.042.

[42] Högblom O, Andersson R. Analysis of thermoelectric generator performance by use of simulations and experiments. J Electron Mater 2014;43:2247-2254. doi:10.1007/s11664-014-3020-x.

[43] Bjørk R. An analytical model for the influence of contact resistance on thermoelectric efficiency. J Electron Mater 2016;45:1301-1308. doi:10.1007/s11664-015-4014-z.

[44] Yin E, Li Q, Xuan Y. Optimal design method for concentrating photovoltaic-thermoelectric hybrid system. Appl Energy 2018;226:320-329. doi:10.1016/j.apenergy.2018.05.127.

[45] Yin E, Li Q, Xuan Y. Thermal resistance analysis and optimization of photovoltaic-thermoelectric hybrid system. Energy Convers Manag 2017;143:188-202. doi:10.1016/j.enconman.2017.04.004.

[46] Yin E, Li Q, Li D, Xuan Y. Experimental investigation on effects of thermal resistances on a photovoltaic-thermoelectric system integrated with phase change materials. Energy 2019;169:172-185. doi:10.1016/j.energy.2018.12.035.

[47] Zhang J, Xuan Y, Yang L. Performance estimation of photovoltaic-thermoelectric hybrid systems. Energy 2014;78:895-903. doi:10.1016/j.energy.2014.10.087.

[48] Zhang J, Xuan Y. Investigation on the effect of thermal resistances on a highly concentrated photovoltaic-thermoelectric hybrid system. Energy Convers Manag 2016;129:1-10. doi:10.1016/j.enconman.2016.10.006.

[49] Mahmoudinezhad S, Rezania A, Rosendahl LA. Behavior of hybrid concentrated photovoltaic-thermoelectric generator under variable solar radiation. Energy Convers Manag 2018;164:443-452. doi:10.1016/j.enconman.2018.03.025.

[50] Chen WH, Lin YX, Wang XD, Lin YL. A comprehensive analysis of the performance of thermoelectric generators with constant and variable properties. Appl Energy 2019;241:11-24. doi:10.1016/j.apenergy.2019.02.083.

[51] Li G, Zhang G, He W, Ji J, Lv S, Chen X, et al. Performance analysis on a solar concentrating thermoelectric generator using the microchannel heat pipe array. Energy Convers Manag 2016;112:191-198. doi:10.1016/j.enconman.2016.01.025.

[52] Shittu S, Li G, Zhao X, Ma X. Series of detail comparison and optimization of thermoelectric element geometry considering the PV effect. Renew Energy 2019;130:930-942. doi:10.1016/j.renene.2018.07.002.

[53] Li G, Diallo TMO, Akhlaghi YG, Shittu S, Zhao X, Ma X, et al. Simulation and experiment on thermal performance of a micro-channel heat pipe under different evaporator temperatures and tilt angles. Energy 2019;179:549-557. doi:10.1016/j.energy.2019.05.040.

[54] Mahmoudinezhad S, Atouei SA, Cotfas PA, Cotfas DT, Rosendahl LA, Rezania A. Experimental and numerical study on the transient behavior of multi-junction solar cell-thermoelectric generator hybrid system. Energy Convers Manag 2019;184:448-455. doi:10.1016/j.enconman.2019.01.081. 
Li G, Shittu S, Ma X, Zhao X. Comparative analysis of thermoelectric elements optimum geometry between photovoltaic-thermoelectric and solar thermoelectric. Energy 2019;171:599-610. doi:10.1016/j.energy.2019.01.057.

[56] Fallah Kohan HR, Lotfipour F, Eslami M. Numerical simulation of a photovoltaic thermoelectric hybrid power generation system. Sol Energy 2018;174:537-548. doi:10.1016/j.solener.2018.09.046.

[57] He H, Liu W, Wu Y, Rong M, Zhao P, Tang X. An approximate and efficient characterization method for temperature-dependent parameters of thermoelectric modules. Energy Convers Manag 2019;180:584-597. doi:10.1016/j.enconman.2018.11.002.

[58] Cheng ZJ, Zhang Z, Jian LH, Yi Q. Temperature distribution and back sheet role of polycrystalline silicon photovoltaic modules. Appl Therm Eng 2017;111:1296-1303. doi:10.1016/j.applthermaleng.2016.10.095.

[59] Xiao J, Yang T, Li P, Zhai P, Zhang Q. Thermal design and management for performance optimization of solar thermoelectric generator. Appl Energy 2012;93:33-38. doi:10.1016/j.apenergy.2011.06.006.

[60] Machrafi H. An extended thermodynamic model for size-dependent thermoelectric properties at nanometric scales: application to nanofilms, nanocomposites and thin nanocomposite films. Appl Math Model 2016;40:2143-2160. doi:10.1016/j.apm.2015.09.044.

[61] Antonova EE, Looman DC. Finite elements for thermoelectric device analysis in ANSYS. ICT 2005. 24th Iinternational Conf. Thermoelectr., 2005, p. 200-3. doi: 10.1109/ICT.2005.1519922.

[62] Ezzat MA. Theory of fractional order in generalized thermoelectric MHD. Appl Math Model 2011;35:4965-4978. doi:10.1016/j.apm.2011.04.004.

[63] Evans DL. Simplified method for predicting photovoltaic array output. Sol Energy 1981;27:555-560.

[64] Zhou J, Yi Q, Wang Y, Ye Z. Temperature distribution of photovoltaic module based on finite element simulation. Sol Energy 2015;111:97103. doi:10.1016/j.solener.2014.10.040.

\section{Graphical abstract}

\section{Highlights}

- Comprehensive photovoltaic-thermoelectric model with contact resistance is provided.

- Three-dimensional numerical study of photovoltaic-thermoelectric is presented.

- Ignoring contact resistances leads to a $7.6 \%$ overestimation of power output.

- Optimum load resistance in hybrid system is different from that in thermoelectric.

\section{Queries and Answers}

Query: Your article is registered as a regular item and is being processed for inclusion in a regular issue of the journal.

If this is NOT correct and your article belongs to a Special Issue/Collection please contact

J.Shanmugam@elsevier.com immediately prior to returning your corrections.

Answer: Yes 
Query: The author names have been tagged as given names and surnames (surnames are highlighted in teal color).

Please confirm if they have been identified correctly.

Answer: Yes

Query: Have we correctly interpreted the following funding source(s) and country names you cited in your article:

EPSRC, United Kingdom? /

Answer: Yes 